\title{
Compensatory Mechanisms Underlie Intact Task-Switching Performance in
}

\section{Schizophrenia}

\author{
Jamadar, S., Michie, P., \& Karayanidis, F.
}

Functional Neuroimaging Laboratory, School of Psychology, University of Newcastle, Australia Centre for Brain and Mental Health Research, University of Newcastle, Australia Schizophrenia Research Institute, Sydney, Australia

Corresponding author:

Dr Frini Karayanidis

Email: frini.karayanidis@newcastle.edu.au

Telephone: +612 49215457

Fax: +612 49216980 


\section{ACKNOWLEDGEMENTS}

This research was supported by an Australian Postgraduate Award and Schizophrenia Research Institute Postgraduate Scholarship to Sharna Jamadar and by funding from the University of Newcastle Research Grants Committee and Hunter Medical Research Institute to Frini Karayanidis and Pat Michie. We thank the Australian Schizophrenia Research Bank (ASRB) and Hunter Medical Research Institute Research Volunteer Register for assistance with recruitment. We wish to thank Matthew Hughes for input into paradigm development, Gavin Cooper for software development, and Gary O'Connor, Yvonne Allen, Marcel Wall and Todd Alchin for assistance with fMRI scanning. 


\begin{abstract}
Individuals with schizophrenia tend to perform poorly on many measures of cognitive control.

However, recent task-switching studies suggest that they show intact task-switching performance, despite the fact that the regions involved in task-switching are known to be structurally and functionally impaired in the disorder. Behavioural, ERP and fMRI measures were used to compare the temporal and spatial dynamics of task-switching performance in individuals with schizophrenia and controls. Consistent with previous studies, RT switch cost and its reduction with anticipatory preparation did not differ between groups. There were also no group differences on cue-locked ERP components associated with anticipatory preparation processes. However, both stimulus- and response-locked ERPs were significantly disrupted in schizophrenia, suggesting difficulty with taskset implementation. fMRI analyses indicated that individuals with schizophrenia showed hyperactivity in the dorsolateral prefrontal cortex and posterior parietal cortex. RT-fMRI and ERP-fMRI associations suggested that individuals with schizophrenia employ compensatory mechanisms to overcome difficulties in task-set implementation and thereby achieve the same behavioural outcomes as controls.
\end{abstract}


Schizophrenia is a major psychiatric disorder which involves a complex set of disturbances of cognition, perception, emotion and social behavior (Barbato, 1998). It is characterized by a range of symptoms, of which hallucinations, delusions, impaired judgment and loss of contact with reality are hallmark features. Cognitive functioning is perhaps one of the most critical determinants of quality of life in schizophrenia, potentially more so than the severity of positive and negative symptoms (Green, Kern, Braff \& Mintz, 2000). Schizophrenia is associated with a broad range of cognitive impairments in areas that include verbal memory, oculomotor control, attentional orienting, decision making, inhibitory control, language, explicit learning and memory, perceptual/motor processing and executive functions (Antonova, Sharma, Morris \& Kumari, 2004; Danckert, Saoud, \& Maruff, 2004). These cognitive impairments are linked to structural and functional abnormalities in a range of brain regions, including the prefrontal cortex (PFC), posterior parietal cortex (PPC) and striatum. Reduced activation of dorsolateral PFC (DLPFC) in patients has been reported in working memory tasks (Barch, 2005; Cannon, Glahn, Kim, van Erp, Karlsgodt, Glahn, van Erp, Therman, Huttunen et al., 2006) and visual oddball paradigms (Morey, Inan, Mitchell, Perkins, Lieberman \& Belger, 2005). In patients, reduction in DLPFC metabolic activity has been associated with reduced P300 amplitude in an auditory oddball task (Molina, Sanz, Munoz, Casado, Hinoiosa et al., 2005) whereas reduced regional cerebral blood flow (rCBF) in the DLPFC has been found during the Wisconsin Card Sorting Task (WCST; Meyer-Lindenberg, Poline, Koh, Holt, Egan et al., 2002). These findings may be related to a reduction in grey matter volume of the DLPFC, as well as impairments in the prefrontalthalamic-cerebellar network (Antonova et al., 2004; Rusch, Spoletini, Wilke, Bria, Di Paola et al., 2007). Structural changes in the anterior cingulate cortex (ACC; Zetzsche, Preuss, Frodl, Watz, Schmitt et al., 2007) may underlie problems with error detection (Kerns, Cohen, MacDonald, Johnson, Stenger et al., 2005; Laurens, Ngan, Bates, Kiehl, \& Liddle, 2003) and conflict detection (Kerns et al., 2005; Neuhaus, Koehler, Opgen-Rhein, Urbanek, Hahn \& Dettling, 2007). Impaired PPC activity in schizophrenia has been attributed not only to a primary functional and structural PPC abnormality (Torrey, 2007; Zhou, Suzuki, Takahasi, Hagino, Kawasaki et al., 2006), but also to compensatory activity in response to impaired DLPFC activity (Quintana, Wong, Ortiz-Portillo, 
Kovalik, Davidson et al., 2003). Given the role of dopamine in schizophrenia, it is perhaps not surprising that structural and functional changes of the basal ganglia and thalamus (Mamah, Wang, Barch, de Erausquin, Gado \& Csernansky, 2007; Morey et al., 2005; Rusch et al., 2007) have been reported to be associated with cognitive deficits in these patients.

The WCST is perhaps the most commonly used test of cognitive control in schizophrenia. Individuals with schizophrenia complete fewer sorting categories than healthy controls and commit more perseverative errors (Everett, Lavoie, Gagnon, \& Gosselin, 2001; Li, 2004; Pantelis, Barber, Barnes, Nelson, Owen \& Robbins, 1999; Prentice, Gold \& Buchanan, 2008; Smith, Large, Cavanagh, Karayanidis, Barrett et al., 1998). WCST performance deficits in schizophrenia have been linked to structural and functional changes in the DLPFC (Bonilha, Molnar, Horner, Anderson, Forster, et al., 2008; Meyer-Lindenberg et al., 2002), temporal lobe (Weinberger, Berman, Suddath \& Torrey, 1992), amygdala (Rusch, Tebartz van Elst, Valerius, Muchert, Thiel et al., 2008), prefrontal-thalamiccerebellar networks (Rusch et al., 2007), and basal ganglia (Stratta, Mancini, Mattei, Daneluzzo, Casachia \& Rossi, 1997). However, as the WCST performance relies on a number of cognitive processes related to attention, memory and problem-solving (Kerns, Nuechterlein, Braver, \& Barch, 2008), poor performance may be attributable to any number of processes. These include a tendency to perseverate with ineffective strategies (see Li et al., 2004 for a discussion), failure to inhibit inappropriate responses (Everett et al., 2001), as well as difficulties with adjusting performance after error feedback (Kerns et al., 2008), applying a learned rule to a new context (Goldberg, Weinberger, Berman, Pliskin \& Podd, 1987), learning a new set (Pantelis et al., 1999) or shifting set (Smith et al., 1998).

Task-switching paradigms have been used to examine set-shifting ability while controlling for other cognitive processes. When switching between simple tasks, reaction time (RT) is longer on switch relative to repeat trials. This switch cost reduces as the time to prepare in advance of a switch trial increases (Karayanidis, Coltheart, Michie \& Murphy, 2003; Koch \& Allport, 2006; Meiran, 2000; Monsell, 2003; Nicholson, Karayanidis, Poboka, Heathcote, \& Michie, 2005; Rogers \& Monsell, 1995; Rubinstein, Meyer \& Evans, 2001). However, even with very long preparatory 
intervals (response-stimulus interval (RSI) in alternating runs paradigms e.g., Rogers \& Monsell, 1995 and cue-stimulus interval (CSI) in cued trials paradigms e.g., Meiran, Chorev \& Sapir, 2000), a residual switch cost still remains, suggesting that anticipatory preparation is not sufficient to equate switch and repeat trials (e.g. Allport, Styles \& Hseih, 1994; Rogers \& Monsell, 1995). Interpretation of the residual switch cost differs between investigators, with some invoking exogenous control processes that cannot be completed until after stimulus onset (e.g. Rogers \& Monsell, 1995; Rubinstein et al., 2001) and others invoking interference from passively dissipating task-set activation or inhibition (e.g., Allport et al., 1994; Mayr \& Keele, 2000).

Event-related potentials (ERPs) locked to the onset of the preparation interval (RSI or CSI) generally show a switch-specific increase in a posterior positivity (Goffaux, Phillips, Sinai \& Pushkar, 2006; Jamadar, Nicholson, Michie \& Karayanidis, in press; Karayanidis et al., 2003; Kieffaber \& Hetrick, 2005; Miniussi, Marzi \& Nobre, 2005; Nicholson et al., 2005; Nicholson, Karayanidis, Davies \& Michie, 2006; Nicholson, Karayanidis, Bumak, \& Michie, 2006; Poulsen, Luu, Davey \& Tucker, 2005; Rushworth, Passingham \& Nobre, 2002; 2005). This differential switch-positivity emerges as early as $150 \mathrm{~ms}$ after cue onset and can be fully resolved prior to stimulus onset in optimal conditions (long CSI, valid task-specific cue). The switch-positivity is likely to index anticipatory preparation processes that are engaged on switch, but not repeat trials, such as category-response (CR) rule activation (Jamadar et al., in press; Karayanidis et al., 2003; Nicholson et al., 2005). Stimuluslocked ERPs also show evidence for differential switch-related activity: switch trials show a decrease in posterior positivity relative to repeat trials, sometimes as early as $150 \mathrm{~ms}$ post-stimulus (Goffaux et al., 2006; Karayanidis et al., 2003; Kieffaber \& Hetrick, 2005; Nicholson et al., 2005; Nicholson, Karayanidis, Bumak, \& Michie, 2006; Nicholson, Karayanidis, Davies \& Michie, 2006; Rushworth et al., 2002; Rushworth et al., 2005). This differential switch-negativity is likely to index effort to overcome interference due to task-set inertia or stimulus-response (S-R) priming as conceptualized by Allport and colleagues (Jamadar et al., in press), or it may reflect exogenous control processes that cannot be initiated until stimulus onset as conceptualized by Monsell and colleagues (Karayanidis et al., 2003). 
fMRI studies have shown that task-switching activates a frontoparietal network (Brass \& von Cramon, 2004; Braver, Reynolds, \& Donaldson, 2003; Jamadar, Hughes, Fulham, Michie \& Karayanidis, in revision; Liston, Matalon, Hare, Davidson \& Casey, 2006; Luks, Simpson, Feiwell, \& Miller, 2002; Ruge, Brass, Koch, Ribin, Meiran \& von Cramon, 2005; Wylie, Javitt \& Foxe, 2006; Yeung, Nystrom, Aronson \& Cohen, 2006). Anticipatory preparation is believed to be subserved by top-down biasing mechanisms that 'pre-activate' task-relevant regions in advance of stimulus onset (Wylie et al., 2006). This top-down signal is believed to originate in the DLPFC (Jamadar et al., in revision; Liston et al., 2006; Luks et al., 2002; Sohn, Ursu, Anderson, Stenger \& Carter, 2000; Yeung et al., 2006), biasing S-R rules in the PPC in advance of the stimulus (Braver et al., 2003; Brass \& von Cramon, 2004; Bunge, Hazeltine, Scanlon, Rosen \& Gabrieli, 2002; Crone, Wendelken, Donohue \& Bunge, 2005; Jamadar et al., in revision; Ruge et al., 2005). Interference-related effects have been shown to be related to concurrent activity of task-irrelevant regions during performance of a task (Yeung et al., 2006).

In a recent study that included behavioural, ERP and fMRI measures (Jamadar et al., in revision), behavioural switch cost on prepared trials was correlated with activity largely in the dorsal premotor cortex $(\mathrm{PMd})$, suggesting that switch cost on prepared trials is proportional to the amount of interference encountered during response preparation. The reduction in switch cost between prepared and non-prepared trials was correlated with activity in the PPC, indicating that preparation serves to facilitate task-set implementation by pre-activating C-R rules in advance of stimulus onset. The cuelocked switch-positivity was correlated with DLPFC and PPC activation, suggestive of a top-down biasing mechanism with DLPFC biasing C-R rules held in PPC during anticipatory preparation. The stimulus-locked switch-negativity was correlated with activity in the cingulate cortex, supporting a role of this component in the resolution of post-stimulus interference arising due to task-set inertia (Allport et al., 1994) or S-R priming (Allport \& Wylie, 2000; Wylie \& Allport, 2000).

\section{Task-Switching Performance in Schizophrenia}

Given that patients with schizophrenia consistently show impairments on the WCST and deficits in the neuroanatomical network involved in task-switching, it is perhaps surprising that there 
is little evidence for a decline in task-switching ability in schizophrenia. Although RT is generally longer in patients relative to controls across all conditions, RT switch cost is usually unaffected (Kieffaber, Kappenman, Bodkins, Shekhar, O’Donnel \& Hetrick, 2006; Kieffaber, O’Donnel, Shekhar \& Hetrick, 2007). Where an increase in RT switch cost has been reported in schizophrenia, it has been attributed to generalized response slowing (Karayanidis, Nicholson, Schall, Meem, Fulham \& Michie, 2006; Meiran, Levine, Meiran \& Henik, 2000). RT switch cost decreases at roughly the same rate for patients and controls as a function of preparation interval, suggesting intact anticipatory preparation (Karayanidis et al., 2006; Kieffaber et al., 2006; Meiran, Levine et al., 2000). This is surprising given that individuals with schizophrenia consistently show a deficit in allocating attention towards anticipatory and response preparation processes (Pritchard, 1986; Reuter, Herzog, Endrass \& Kathmann, 2006), as indexed electrophysiologically by attenuation of the contingent negative variation (CNV) in ERP studies (Pritchard, 1986).

The first systematic investigation of the ERP correlates of task-switching in schizophrenia was conducted by Karayanidis et al. (2006) using a paradigm that with a predictable sequence of switch and repeat trials (i.e., alternating runs paradigm). Although patients showed no increase in RT switch cost when correcting for generalized RT increase (see also Meiran, Levine et al., 2000), ERP components showed substantial differences between patient and control groups. Consistent with previous evidence showing an overall decrease in arousal or attention and preparation to respond to an impending stimulus (McCallum \& Walter, 1968; Pritchard, 1986; Reuter et al., 2006), and reduced anticipation for the impending stimulus (Damen \& Brunia, 1994) in schizophrenia, individuals with schizophrenia showed a reduced CNV-like negativity preceding stimulus onset at the long preparation interval for both switch and repeat trials. In ERPs time-locked to the onset of the preparatory interval (RSI), patients showed an intact differential switch-positivity at the short preparation interval (150ms), that was entirely absent at the long preparation interval (600 \& 1200ms). In addition, the onset of the stimulus-locked switch-negativity was delayed by $200 \mathrm{~ms}$, and the amplitude of both stimulus-locked and response-locked lateralised readiness potentials (LRPs) was attenuated in the schizophrenia group relative to controls. This pattern of results is consistent with less efficient 
anticipatory preparation, delayed in C-R rule implementation (Jamadar et al., in press), and reduced response preparedness (Coles, Bernstein \& Fournier, 1995). Therefore, Karayanidis et al. (2006) concluded that patients use relatively suboptimal anticipatory preparation processes compared to controls and tend to employ more post-stimulus-related strategies to achieve a similar outcome to controls.

In contrast, Kieffaber et al. (2007) found no ERP or behavioral evidence for deficient taskswitching performance in patients. In a cued-trials paradigm with a single long CSI of $1200 \mathrm{~ms}$, the switch-positivity did not differ between patients and controls, and while the stimulus-locked P3b component was smaller in patients, neither group showed a switch-negativity. Paradigm differences between the two studies may be responsible for such different outcomes. There is evidence that alternating runs paradigms require more endogenously triggered switching between tasks, whereas cued trials paradigms require more externally driven switching between tasks. Karayanidis et al. (2006) employed an alternating runs paradigm with four preparation intervals and univalent stimuli with four exemplars per task and bivalent responses. That is, each stimulus only included exemplars from one of the two tasks (line drawing or picture), but each hand was mapped to a response on both tasks (i.e. left hand may be 'animal' for the picture task and 'straight' for the line task). Kieffaber et al. (2007) used a cued trials paradigm with a single preparation condition, bivalent stimuli and univalent responses. Each stimulus consisted of two shapes, and participants were required to make a 'same' or 'different' judgment based on size or shape with 'same' mapped to one hand and 'different' to the other. Thus, the studies differed in the use of internal vs. external cues, one vs. many preparation intervals, bivalent vs. univalent stimuli, and bivalent vs. univalent response sets. These parameters are likely to affect the employment of endogenous vs. stimulus-driven cueing (Brown \& Marsden, 1988) and the engagement of anticipatory preparation (Altmann, 2004), leading to different task strategies.

\section{The Present Study}

In the present study, we examine task-switching performance in schizophrenia using a cuedtrials paradigm with a long CSI (700ms) and both informative and non-informative cues. Informative 
cues allow for anticipatory preparation to occur before stimulus onset, whereas non-informative cues are not mapped to either task and therefore merely signal the timing of the upcoming stimulus which itself provides task identity information. This paradigm included a number of features similar to those included in Karayanidis et al.'s (2006) study, including bivalent responses, as well as inclusion of an unprepared condition (i.e., non-informative cues) and other features similar to Kieffaber et al. i.e., cued-trials and bivalent stimuli. The current study will be able to address some of the factors that may have contributed to the discrepant results in these two studies.

In an earlier study on a normative sample (Jamadar et al., in press, Experiment 2), this paradigm produced evidence for two distinct cue-locked positivities. An early posterior informativepositivity differentiated informative from non-informative cues around $300 \mathrm{~ms}$ post-cue and was argued to index activation of the task goal. This was followed by a later switch-positivity that differentiated informatively cued switch and repeat trials around $450 \mathrm{~ms}$ post-cue and was consistent with C-R rule activation (Jamadar et al., in press; in revision; Swainson, Jackson \& Jackson, 2006). If there is any evidence for deficient anticipatory preparation processes in schizophrenia, we will be able to identify whether these affect more generic vs. switch-specific preparation processes.

We used a reduced version of this paradigm (informative cues only) to examine fMRI correlates of task-switching in the same group of individuals with schizophrenia. Despite the wealth of fMRI studies investigating set-shifting ability using the WCST in schizophrenia, no study has as yet examined the fMRI correlates of task-switching in schizophrenia. Previous fMRI studies of taskswitching suggest the involvement of a frontoparietal network encompassing the DLPFC and PPC. DLPFC activity has been shown to be impaired in schizophrenia (Antonova et al., 2004; Bonilha et al., 2008; Meyer-Lindenberg et al., 2002; Rusch et al., 2007), and the PPC has been suggested to play a compensatory role when DLPFC deficits affect behavior (Quintana et al., 2003). Therefore, we expect that patients may show reduced DLPFC activation and compensatory PPC activity in this paradigm.

\section{Method}

\section{Participants}


Sixteen individuals with schizophrenia were recruited from the Australian Schizophrenia Research Bank and community groups. One participant withdrew after the first session, and three others were excluded due to visual impairment (severe myopia that could not be corrected for with MR compatible lenses in the fMRI session), unsuitability for the fMRI component (metal implants) and inability to complete the task. The remaining twelve participants with schizophrenia completed the ERP session, and eleven completed the fMRI session. Sixteen control participants were recruited from the community, largely through the Hunter Medical Research Institute's Research Register. Four control participants were excluded due to visual impairment (one due to severe myopia, another due to colour blindness), suspected schizoaffective disorder and unsuitability for the fMRI component (metal implants). The remaining twelve control participants were matched to patients based on age and gender. All controls completed the ERP session, and all but one (matched to the participant in the patient group) completed the fMRI session.

Both groups were clinically assessed using the Diagnostic Interview for Psychoses (Castle, Jablensky, McGrath, Carr, Morgan et al., 2006). Current symptomatology was assessed using the Schedule for the Assessment of Negative Symptoms (SANS; Andreasen, 1984a) and Schedule for the Assessment of Positive Symptoms (SAPS; Andreasen, 1984b). IQ was estimated using the National Adult Reading Test (NART; Nelson \& Wilson, 1991). Demographic data, symptom ratings and medication data are shown in Table 1. The schizophrenia group did not differ from the control group in age or gender and showed significant decrement in global functioning (assessed by Global Assessment of Functioning, GAF) and significant positive and negative psychotic symptoms. The protocol was approved by the University of Newcastle Human Research Ethics Committee and the Hunter New England Area Health Human Research Committee. All participants gave written informed consent before participating and received monetary reimbursement to cover travel costs.

\section{Stimuli and Tasks}

The task was presented in Presentation (Neurobehavioral Systems). A square box was outlined in grey (100 x 100 pixels) against a black background on a computer monitor for the duration of the experiment. Each trial began with the presentation of an informative or non-informative cue 
consisting of a fixation cross ( 40 x 40 pixels), which remained on the screen for the entire cuestimulus interval of $700 \mathrm{~ms}$ and was replaced by the stimulus. Non-informative cues were presented in grey and informative cues were presented in one of two 'hot' (red, orange) and two 'cold' (blue, green) colors that were mapped to one of the two tasks. Cue color was never repeated on successive trials to eliminate any confounding effect of cue identity repetition (Logan and Bundesen, 2003). On informatively cued trials, an informative cue was presented in one of the cue colors and the stimulus was white. On non-informatively cued trials, the non-informative cue (grey fixation cross) was replaced by a stimulus in one of the cue colors.

Stimuli were letter-digit pairs (e.g., A4) presented in 12pt SimSun font. The position of the letter and digit was randomized between trials (i.e. A4 or 4A). On each trial, participants responded to either the letter or the digit. For the letter task, participants classified the letter as vowel (A, E, I, U) or consonant $(\mathrm{G}, \mathrm{K}, \mathrm{M}, \mathrm{R})$. For the digit task, they classified the digit as odd $(3,5,7,9)$ or even $(2,4,6$, 8). Participants used their left and right index fingers to respond. Stimulus-response mapping and cuetask mapping were counterbalanced across participants. Only incongruent character pairs (letter-digit combinations) were presented, that is, the task-irrelevant character was always mapped to a response with the other hand (e.g., A4: even and vowel mapped to the different hands) ${ }^{1}$. The stimulus onset asynchrony (SOA; cue to cue) varied between 2.5 and $7 \mathrm{sec}$ on an exponential scale, with a mean of 4 sec. Following a response, the stimulus was removed and was followed $300 \mathrm{~ms}$ later by a feedback tone. Correct responses were followed by a $1000 \mathrm{~Hz}$ tone, and incorrect responses were followed by an Microsoft Windows 'dong' tone. The response-cue interval was determined by the SOA on that particular trial after subtracting CSI, RT and feedback interval. The overall probability of a switch trial was $50 \%$ in a pseudorandom sequence that included no more than three consecutive switch or repeat trials.

\footnotetext{
${ }^{1}$ On trials with congruent stimuli, it is possible for participants to perform the wrong task yet still make the correct response. In order to overcome this confound, we used incongruent stimuli only. This introduced the possibility that some participants may have used a simple S-R mapping reversal rather than switch between tasks. Although possible, this is very unlikely. The task included a broad array of 8 letters and 8 numbers and randomization of letter/number position. So even without the congruent letter-digit pairs, there were 64 different letter-digit/digit-letter combinations presented in a randomized order, making it very difficult for the participant to detect that S-R reversal was a potential alternative strategy.
} 
In the EEG session, participants sat upright, and visual stimuli were presented on a computer monitor viewed from approximately $90 \mathrm{~cm}$ (visual angle $1^{\circ}$ ). In the fMRI session, participants lay supine in the scanner bore, holding a response device in each hand. Visual stimuli were back projected onto a screen positioned approximately $2 \mathrm{~m}$ from the scanner bore entrance. Subjects viewed the stimuli through a mirror mounted on a head coil. Tones were delivered binaurally through MRI compatible piezoelectric headphones. Responses and scanner TTL pulses were passed through an inhouse developed 'response box', which was connected to a laptop computer. Responses, stimulus timing and slice acquisition (TTL pulses) were recorded.

\section{Procedure}

Participants completed three sessions scheduled about one week apart. The first session included clinical assessment and the first training session. Participants practiced each task alone (100 trials per task), and switching between the tasks with an informative cue and switching with a noninformative cue (100 trials/cue type). The other two sessions included either ERP or fMRI data acquisition: approximately half the participants $(n=11)$ completed the ERP component in the second session and the other half $(\mathrm{n}=13)$ completed the fMRI component in the second session. Regardless of whether participants completed the ERP or fMRI component in the second session, the second session began with a further training session (as above but with blocks of 50 trials). Participants received no further training before the third session.

In the ERP session, participants completed two blocks of task-switching with informative cues and two with non-informative cues. This resulted in a total of 176 trials per trial type (switch, repeat) for each cue type. Due to scanning time constraints, only the informative cue condition was completed in the fMRI session (176 trials per trial type). Participants were instructed to respond as quickly as possible whilst maintaining a high level of accuracy. Following each run, RT and percent accuracy feedback was displayed and participants were encouraged to monitor and improve their performance.

\section{Data Analysis}

The first two trials of every run, trials associated with an incorrect response, trials immediately following an incorrect response, and trials with a response occurring outside a 200-2000ms window 
after stimulus onset were excluded from behavioural, ERP and fMRI analyses. In the ERP data, this resulted in a $13 \%$ reduction in data for controls and a $24 \%$ reduction for patients. In fMRI data, this resulted in an $11 \%$ reduction in data for controls and a $21 \%$ reduction for patients. Due to equipment malfunction, the ERP data for one control subject was lost, resulting in $n=11$ controls and $n=12$ patients in the ERP analyses and $n=11$ in both groups in the fMRI analyses. For both behavioural and ERP analyses, degrees of freedom for factors with more than two levels were adjusted using Greenhouse-Geisser correction for the violation of the assumption of sphericity (Vasey and Thayer, 1987).

\section{EEG Recording and Data Analysis}

EEG was recorded using a Quik-cap from 28 scalp electrodes and two mastoid electrodes referenced to the nose electrode. Vertical and horizontal EOG were recorded via electrodes positioned above and below the left eye, and on the outer canthi of each eye, respectively. EEG and EOG were continuously sampled at 500Hz/channel on a Synamps 1 system (Neuroscan) with a bandpass of $0.01-$ $30 \mathrm{~Hz}$ (roll-off: $12 \mathrm{~dB}$ per octave) and a $50 \mathrm{~Hz}$ notch filter. Continuous EEG files were re-referenced to the average of left and right mastoids to be consistent with previous methods in our laboratory (e.g. Karayanidis et al. 2003). Vertical eyeblink artifact was corrected in the continuous EEG files using the algorithm developed by Semslitch, Anderer, Schuster and Presslich (1986) as implemented by Neuroscan software. These files were then inspected and sections of EEG contaminated with channel saturation or noise were excluded from further analysis. On average this resulted in 130-150 trials per trial type.

Cue-, stimulus-, and response-locked epochs were created by extracting 1400ms epochs around the onset of the cue (-200 to $1200 \mathrm{~ms})$, stimulus (-200 to $1200 \mathrm{~ms})$ and response (-1000 to $200 \mathrm{~ms})$ and averaged separately for switch and repeat trials and for informative and non-informative cues. Cuelocked waveforms were baseline corrected over the entire prestimulus baseline (-200ms to $0 \mathrm{~ms})$, stimulus-locked waveforms were baseline corrected from -50 to $50 \mathrm{~ms}$ to account for the shifting prestimulus baseline (Karayanidis et al., 2003), and response-locked waveforms were baseline corrected over -1000 to $-700 \mathrm{~ms}$. Mean amplitude windows for analyses were extracted using 
EEGDisplay software (Fulham, 2005). Bonferroni correction for multiple comparisons was made by dividing the $\mathrm{p}$-value by the number of comparisons made. Scalp topographies show difference waveforms (cue-locked: informative minus non-informative and informative switch minus repeat; stimulus-locked: informative switch minus repeat; response-locked: informative minus noninformative).

\section{MR Image Acquisition and Data Analysis}

Magnetic resonance images were acquired using a Siemens Vision 1.5 T whole-body MR scanner, equipped with a Siemens quadrature head coil. Anatomical images were collected using a T1-weighted MPRAGE protocol $\left(\mathrm{TR}=9.7 \mathrm{~ms}\right.$, flip angle $=12^{\circ}, 224 \times 256$ matrix, FoV $=250 \mathrm{~mm}$, voxel size $=1 \times 1 \times 1 \mathrm{~mm}, 164$ slices). Functional images were acquired using a T2*-weighted EPI sequence $\left(32\right.$ slices, $\mathrm{TR}=3.839, \mathrm{TE}=70 \mathrm{~ms}$, flip angle $=90^{\circ}$, Fov $=256 \mathrm{~mm}, 64 \times 64$ matrix, voxel size $=4 \times 4 \times 4$ mm, 190 scans per run). EPIs were acquired as 32 interleaved slices (no gap) beginning at the top of the head and positioned according to the anterior-posterior commissural line, maximizing brain volume imaged. Image pre-processing and subsequent statistical analyses were performed using SPM2 (Wellcome Department of Neurology, London). The first 5 images from each imaging run were discarded to allow for T1 saturation effects. Differences in EPI slice acquisition timing were corrected using the central slice as reference. Imaging time series were then realigned to the first EPI image and a mean realigned EPI image was created. Motion was corrected using a rigid-body rotation and translation correction and unwarping (Andersson, Hutton, Ashburner, Turner \& Friston, 2001). Each participant's T1 image was coregistered to the mean image normalized to the T1 template provided with SPM2. The parameters from this transformation were then applied to all EPI images. Accuracy of registration between functional and structural data was assessed by visual inspection of the overlay of each individual subjects' mean EPI and T1 image. Normalised EPIs were then smoothed with a $10 \mathrm{~mm}$ FWHM Gaussian kernel. Slice and volume artifact correction occurred prior to slice-time correction, and spatial smoothing, respectively (Mazaika, Whitfield \& Cooper, 2005). Slices and volumes deviating in intensity by $+/-3 \mathrm{SD}$ from the individual mean were removed from 
the time-series by creating a weighted vector that was included in the model as a covariate of no interest.

For first level analyses, fMRI time series were analysed by fitting a convolved canonical HRF and its temporal derivative (Josephs, Turner \& Friston, 1997) to the onset of the fixation cross for switch and repeat trials, separately ${ }^{2}$. Prior to model estimation, all images were globally scaled and time series were filtered to remove low frequency signals $(<60 \mathrm{~s})$. For each subject, each run was modelled separately. Errors were modelled as a separate factor, resulting in three modelled factors for each run (informatively cued switch, informatively cued repeat, errors). On average there were 74 trials each for informatively cued switch and repeat trials and 25 error trials for each subject.

Second level analysis consisted of a random effects analysis across subjects. Contrast images for the informatively cued switch $>$ repeat and the informatively cued repeat $>$ switch contrasts from all participants were submitted to one sample t-tests. Paired-samples t-tests were conducted to examine differences between patients and controls. Contrasts were thresholded at $p<.005$ (uncorrected), followed by a cluster-wise threshold of $\mathrm{p}<.05$ (corrected for multiple comparisons, $\mathrm{K}=11$ contiguous voxels). Anatomical loci were determined by converting cluster maxima to Talairach space (Talairach \& Tournoux, 1988; http://imaging.mrccbu.cam.ac.uk/imaging/MniTalairach) and entering these coordinates into the Talairach Daemon (Lancaster, Woldorff, Parsons, Liotti, Frietas et al., 1997). This output was cross-checked using the atlases of Talairach and Tournoux (1988) and Damasio (2005).

\section{Relationship between fMRI measures and behavior / ERP measures}

Multiple regression analyses examined RT-fMRI and ERP-fMRI relationships for each group using the method described by Horovitz and colleagues (Horovitz , Skudlarski \& Gore, 2002; Horovitz, Rossion, Skudlarski \& Gore, 2004). This involves using the amplitude of ERP components as regressors to examine the cortical regions that correlate with the scalp-recorded electrophysiology. Four separate analyses examined the relationship between the informatively cued switch > repeat contrast and RT and ERP outcomes for each group. The first two analyses examined the relationship

\footnotetext{
${ }^{2}$ Examination of cue- stimulus- and response-locked fMRI activity in our previous study (Jamadar et al., in revision) showed no difference in activation due to the poor temporal resolution of the BOLD signal.
} 
between the informatively cued switch > repeat contrast and both the RT switch cost and the late cuelocked differential positivity ERP amplitude for each group. The second two analyses examined the relationship between the informatively cued switch > repeat contrast and the amplitude of the stimulus-locked switch-negativity measured 300-400ms and 500-600ms for both groups. Pearson correlation values were extracted from the peak of activity using the VBM toolbox (http://dbm.neuro.uni-jena.de/vbm/). Similar to the fMRI contrast analyses, these analyses were thresholded at $\mathrm{p}<.005$ (uncorrected), followed by a cluster-wise threshold of $\mathrm{p}<.05$ (corrected for multiple comparisons, $\mathrm{K}=11$ contiguous voxels). Scatterplots of correlations were created by extracting mean amplitude within regions-of-interest (ROIs) defined as an $8 \mathrm{~mm}^{3}(2 \times 2 \times 2 \mathrm{~mm})$ box around the peak voxel in the contrast of interest. Contrast values were extracted using MarsBaR (Brett, Anton, Valabregue \& Poline, 2002).

\section{Results}

\section{Behavioral Data}

Error rate, RT and RT switch cost are shown in Figure 1 for both informative and noninformative cues from the ERP session and from the informative cues from the fMRI session. On informatively cued trials that were common to both sessions, there was a generalized slowing of RT in the fMRI session $(F(1,43)=7.06, p=.011)$, but no differential effect of session on switch and repeat trials, consistent with previous studies (Jamadar et al., in revision, Koch, Ruge, Brass, Rubin, Meiran \& Prinz, 2003).

RT data from the ERP session were analyzed using a 2 group (schizophrenia, control) x 2 cue type (informative, non-informative) x 2 trial type (switch, repeat) repeated-measures ANOVA. Responses on informatively cued trials were faster than non-informatively cued trials $(F(1,22)=181.66, \mathrm{p}<.001)$, and on repeat trials were faster than switch trials $(\mathrm{F}(1,22)=57.25, \mathrm{p}<.001$; Figure 1B). Switch cost was significantly larger on non-informatively compared to informatively cued trials $(F(1,22)=29.84, p<.001$; Figure 1C). Despite overall slower RT for patients $(F(1,22)=15.23$, $\mathrm{p}=.001$ ), group did not interact with any other factor (all $\mathrm{F}<1.26$ ). So patients and controls did not differ in task-switching performance with or without preparation. More errors were made on non- 
informatively cued trials and on switch trials $(\mathrm{F}(1,22)=26.74, \mathrm{p}<.001 ; \mathrm{F}(1,22)=18.55$, $\mathrm{p}<.001$; Figure 1A). Patients made marginally more errors than controls $(\mathrm{F}(1,22)=3.56, \mathrm{p}=.072)$, however again group did not interact with any other factor (all $\mathrm{F}<1.0$ ).

On RT data from the fMRI session (Figure 1, right), informatively cued switch trials were associated with slower RT and more errors than repeat trials $(F(1,21)=25.25, \mathrm{p}<.001 ; \mathrm{F}(1,21)=5.98$, $\mathrm{p}=.023)$. Again, patients were slower overall than controls $(\mathrm{F}(1,21)=24.53, \mathrm{p}<.001)$ but there was no group effect on switch costs for either RT or error rate $(\mathrm{F}<1.0)$.

\section{ERP Data}

\section{Cue-Locked Waveforms}

Cue-locked waveforms (Figure 2A) were characterized by a broad positivity over 200-600ms that was followed by a broad CNV-like negativity leading up to stimulus onset. Informatively cued trials showed a larger positivity relative to non-informatively cued trials emerging before $200 \mathrm{~ms}$ frontally and extending to $600 \mathrm{~ms}$ parietally. In addition, there was a small but significant increase in positivity for informatively cued switch trials relative to informatively cued repeat trials emerging after 500ms centroparietally. The topography of these differential effects (difference waveforms), shown in Figure 2A (right), indicates that, for controls, the early increase in positivity for informative relative to noninformative trials shows maximal positivity at centroparietal midline. The later increase in positivity for informative switch relative to repeat waveforms was also maximal centroparietally, however it extended to a greater extent to left and right lateralised regions. These topographical effects are consistent with our previous results (Jamadar et al., in press). Patients showed similar topographies for each effect as controls, with a slightly more left lateralised informative switch repeat difference than controls

The early increase in positivity for informative relative to noninformative trials, and the later increase in positivity for informative switch relative to repeat trials, were targeted by mean amplitude measures over $300-400 \mathrm{~ms}$ and $500-600 \mathrm{~ms}$ and analyzed separately with a 3 cue type (informatively cued repeat, informatively cued switch, non-informatively cued) x 3 electrode (Fz, $\mathrm{Cz}, \mathrm{Pz})$ x 2 group (schizophrenia, control) mixed ANOVA with planned comparisons of informative vs. non- 
informative cues and informatively cued switch vs. informatively cued repeat cues. The effect of group was not significant in either window (both $\mathrm{p}>$.417) and did not interact with any other factor.

The main effect of electrode was significant in both windows $(F(2,42)=40.41, p<.001 ; F(2,42)=34.98$, $\mathrm{p}<.001$ ) indicating that the cue-locked positivity was larger parietally. Over both analysis windows, this positivity was larger for informative cues than non-informative cues $(F(1,21)=39.39, p<.001$; $\mathrm{F}(1,21)=12.72, \mathrm{p}=.002)$ and this informative-positivity was larger centro-parietally $(\mathrm{F}(1,21)=10.73$, $\mathrm{p}=.004 ; \mathrm{F}(1,21)=32.64, \mathrm{p}<.001)$. In the early window, informative switch cues tended to show a smaller positivity frontally and a larger positivity parietally compared to informative repeat cues $(\mathrm{F}(1,21)=7.92, \mathrm{p}=.010)$. The parietal switch-positivity continued to be significant over $500-600 \mathrm{~ms}$ $(\mathrm{F}(1,21)=9.20, \mathrm{p}=.006)$. Thus, consistent with previous findings, ERP waveforms showed an informative-positivity (Jamadar et al., in press) and a small but significant switch-positivity (Karayanidis et al., 2003; Nicholson et al., 2005; Jamadar et al., in press), however neither effect differed between control and schizophrenia groups.

\section{Stimulus-Locked Waveforms}

Stimulus-locked waveforms (Figure 2B) differed substantially between informatively and noninformatively cued trials especially over the central N2 / parietal early positivity (300-400ms) and around the parietal late positive component (LPC) / frontal slow wave (SW). These were targeted with two mean amplitude windows (300-400ms and 500-600ms, respectively) and analyzed with a 2 group x 2 cue type (informative, non-informative) x 2 trial type (switch, repeat) x 3 midline electrode mixed ANOVA.

In the early analysis window (300-400ms), non-informatively cued trials showed a larger positivity than informatively cued trials $(\mathrm{F}(1,21)=26.27, \mathrm{p}<.001)$ especially over centro-parietal sites $(\mathrm{F}(2,42)=21.99, \mathrm{p}<.001)$. Following informative cues, switch trials resulted in a smaller centroparietal positivity or larger negativity relative to repeat trials (trial type $x$ electrode: $F(2,42)=9.72$, $p=.001$; cue $x$ trial $x$ electrode: $F(2,42)=5.78, p=.014)$. These effects were not modulated by group, although a significant electrode $\mathrm{x}$ group interaction $(\mathrm{F}(2,42)=4.01, \mathrm{p}=.046)$ reflected a larger frontocentral negativity in the schizophrenia group. Scalp topographies (Figure 2B, right) of difference waveforms 
confirmed that the increase in negativity for informative switch relative to repeat trials showed a bilateral centroparietal topography for both controls and patients.

In the later window (500-600ms), activity differed substantially between the two groups (group: $\mathrm{F}(1,21)=9.15, \mathrm{p}=.006$; group $\mathrm{x}$ electrode: $\mathrm{F}(2,42)=5.42, \mathrm{p}=.013$; group $\mathrm{x}$ cue: $\mathrm{F}(1,21)=8.44, \mathrm{p}=.008$; group $\mathrm{x}$ cue $\mathrm{x}$ trial: $\mathrm{F}(1,21)=7.33, \mathrm{p}=.013)$. For non-informatively cued trials, patients showed only a smaller parietal positivity than controls (group: $\mathrm{F}(1,21)=3.35, \mathrm{p}=.081$; group $\mathrm{x}$ electrode: $\mathrm{F}(2,42)=3.58, \mathrm{p}=.049)$. This group difference was amplified on informatively cued trials. The late positivity was much smaller for patients than controls, with the effect more pronounced frontocentrally (group: $\mathrm{F}(1,21)=12.04, \mathrm{p}=.002$; group $\mathrm{x}$ electrode: $\mathrm{F}(2,42)=5.24, \mathrm{p}=.017)$. In addition, the group $\mathrm{x}$ trial type effect $(\mathrm{F}(1,21)=5.16, \mathrm{p}=.034)$ indicated a significantly smaller late positivity for switch compared to repeat trials in the controls $(\mathrm{F}(1,10)=7.53, \mathrm{p}=.021)$ but no switch vs. repeat differentiation in patients $(\mathrm{F}<1)$. These effects are confirmed in the scalp topographies (Figure 2B, right), which show a centroparietal maximum for the informative switch - repeat difference for controls but not patients.

In summary, stimulus-locked waveforms showed an early parietal positivity that was larger for non-informatively relative to informatively cued trials and smaller centro-parietal positivity for informatively cued switch relative to repeat trials. The latter effect corresponds to the beginning of the switch-negativity reported previously (Jamadar et al., in press; Karayanidis et al., 2003). This early positivity did not differ between groups. Controls also showed a later centroparietal positivity that was larger for informatively than non-informatively cued trials and for informatively cued repeat than switch trials. This effect is a continuation of the switch-negativity observed in the earlier window. Patients showed no evidence of an LPC for informatively cued trials and no differentiation between informatively cued switch and repeat trials.

\section{Response-Locked Waveforms}

Response-locked waveforms (Figure 2C) provide information regarding the processes contributing to a response and tend to overlap the later part of stimulus-locked ERP waveforms. In controls, informatively cued waveforms showed a large centroparietally maximal negative pre- 
response complex spanning over 700 to $100 \mathrm{~ms}$ before response onset (Figure 2C; see also Jamadar et al., in press), whereas non-informatively cued waveforms showed little deviation from baseline. This increase in centroparietal positivity is evident in the informative - noninformative scalp topography shown (Figure 2C, right). Over -550 to $-450 \mathrm{~ms}$, this pre-response complex was larger for informative relative to non-informative cues $(\mathrm{F}(1,21)=24.76, \mathrm{p}<.001)$. It also resulted in a significant main effect of group $(\mathrm{F}(1,21)=4.68, \mathrm{p}=.042)$ as well as group $\mathrm{x}$ trial type $(\mathrm{F}(1,21)=4.81, \mathrm{p}=.040)$ and group $\mathrm{x}$ cue type $(\mathrm{F}(1,21)=4.62, \mathrm{p}=.043)$ interactions. The difference between informatively and non-informatively cued trials was larger for controls than patients $(F(1,21)=5.70, p=.027)$. In addition, on noninformatively cued trials, the negativity was larger for switch compared to repeat trials in the patient $(\mathrm{F}(1,11)=7.45, \mathrm{p}=.020)$ but not the controls $(\mathrm{F}<1)$ group. In summary, individuals with schizophrenia produced a smaller pre-response negativity on informatively cued (i.e., prepared) trials than controls, as well as a larger negativity for non-informatively cued switch (i.e. unprepared switch) trials than controls.

\section{fMRI Results}

Figure 3 shows regions activated during informatively cued trials for switch > repeat in control and schizophrenia groups (Table 2). Note that these data were acquired using an identical paradigm to that for the informatively cued ERP condition. fMRI data were not available for the noninformatively cued condition. Controls activated a frontoparietal network encompassing the left superior/medial frontal gyri (SMA; Mayka, Corcos, Leurgans, \& Vaillancourt, 2006), left DLPFC (MFG) and bilateral PPC (precuneus; Figure 3, Table 2). The schizophrenia group also showed activation in the left DLPFC (IFG) and left PPC (precuneus), but did not uniquely activate any regions not activated by controls (schizophrenia > control contrast). As both groups showed activity in the left DLPFC and PPC, ROI analyses were conducted to examine whether activation level differed between groups. As shown in Figure 3 (bottom), activation in both left DLPFC $(\mathrm{t}(10)=1.56, \mathrm{p}=.07)$ and left PPC $(\mathrm{t}(10)=2.71, \mathrm{p}=.010)$ was greater in the schizophrenia compared to the control group.

In the repeat > switch contrast (Figure 4), only the right MTG was activated in controls (A), whereas the schizophrenia group (B) showed activation in a broad frontoparietal network 
encompassing bilateral DLPFC/FPC (SFG/MFG), bilateral DMPFC, left ACC, right primary motor cortex (Mayka et al., 2006), left PPC (precuneus), left posterior cingulate and right superior and middle temporal gyri (Table 3). The schizophrenia vs. control contrast for repeat > switch is shown in Figure 4C. Given the subtractive nature of the group contrast, positive contrast values represent greater activity in the schizophrenia > control contrast for task-repetition compared to task-switching, whereas negative contrast values represent greater activity in the opposite contrast, i.e., control > schizophrenia contrast for task-switching compared to task-repetition. Task repetition resulted in greater activation in the left DLPFC (SFG: $t(10)=4.75, \mathrm{p}<.001$; MFG: $(\mathrm{t}(10)=3.04, \mathrm{p}=.006)$, bilateral DMPFC (left medial frontal gyrus: $\mathrm{t}(10)=4.66, \mathrm{p}<.001$; right: $\mathrm{t}(10)=3.54, \mathrm{p}=.002$ ), and left PHG $(\mathrm{t}(10)=5.62, \mathrm{p}<.001)$ for the schizophrenia group compared to the control group (Figure 4 bottom, positive values). In the reverse contrast, task-switching resulted in greater activation in bilateral ACC (left cingulate: $\mathrm{t}(10)=3.21, \mathrm{p}=.004$; right $=\mathrm{t}(10)=3.77, \mathrm{p}=.001$ ), and bilateral red nucleus (left: $(\mathrm{t}(10)=5.30, \mathrm{p}<.001 ;$ right: $\mathrm{t}(10)=8.50, \mathrm{p}<.001)$ for the control group relative to the patient group (Figure 4C, bottom, negative values).

\section{Correlations between fMRI measures and RT/ERP measures}

Table 4 shows Talairach coordinates, t-values (informative switch - repeat) and r-values for correlations between informatively cued switch > repeat fMRI contrast and RT switch cost and switch-positivity amplitude for both groups. It is important to note that the regions of fMRI activity that show significant correlations with RT and ERP effects are not necessarily the same regions as those revealed in the fMRI contrasts shown in Tables 2-3 and Figure 3. This occurs because variability across individuals will be included in the error term of the GLM in the fMRI contrasts whereas by including RT or ERPs effects in the model, variance across individuals due to these effects is partitioned out of the error term, revealing their significance. A similar approach has been taken by Jamadar et al. (in revision) and Forstmann, van den Wildenberg \& Ridderinkhof (2008).

As shown in Figure 5, for controls, RT switch cost was positively correlated with switch > repeat activity in bilateral FPC (MFG), left VLPFC (IFG), left PMv, bilateral PPC (precuneus) and right posterior cingulate. In the schizophrenia group, this relationship was only evident in the PMd 
(Mayka et al., 2006) and bilateral PPC (precuneus). As both groups showed significant correlation of the bilateral PPC with switch cost, ROI analyses were conducted to examine whether the magnitude of activation differed across groups (Figure 5). There was no group difference in the left PPC $(\mathrm{t}=$ 0.54), however the schizophrenia group showed marginally greater activity in the right PPC relative to controls $(\mathrm{t}(10)=1.66, \mathrm{p}=.06)$. As shown in Figure 6, the cue-locked switch-positivity was positively correlated with switch > repeat activity in the right PM (Mayka et al., 2006), right VLPFC (IFG), right ACC and left PPC (IPL) in the control group and with left PMd and bilateral PPC (precuneus) in the schizophrenia group. ROI analyses showed the schizophrenia group showed marginally greater activity in the left PPC relative to controls $(\mathrm{t}(10)=1.89, \mathrm{p}=.05)$. It is important to note that significant correlations between ERP and fMRI measures do not necessarily indicate that the location of the fMRI activity is the source of that ERP component but rather that fMRI activity in that location covaries with the amplitude of the ERP component.

Table 5 shows Talairach coordinates, $\mathrm{t}$ values and $\mathrm{r}$ values for correlations between informatively cued switch > repeat activity and the mean amplitude of the stimulus-locked switchnegativity measured over 300-400ms and 500-600ms. In controls, the amplitude of the switchnegativity in the early window was positively correlated with switch > repeat activity in bilateral FPC (medial frontal gyrus; Figure 7A), whereas amplitude in the later window was correlated with activity in left FPC (medial frontal gyrus), bilateral ACC, right PM (precentral gyrus) and right PPC (IPL). Similar regions were correlated with switch-negativity amplitude in the schizophrenia group, however they showed temporal differences (Figure7B). Specifically, while the early switch-negativity was correlated with switch > repeat activity in bilateral ACC, left PM (precentral gyrus) and left globus pallidus, the later part of the switch-negativity was correlated with activity in the right PPC (IPL) and right FPC (medial frontal gyrus). As both patients and controls showed activity in the right PPC and in the right FPC and bilateral ACC, albeit with temporal differences, contrast values were extracted from ROIs in order to examine activation differences between the groups. There was no group difference in activation of right FPC and PPC (both $t<1$ ), however, bilateral ACC activation tended to 
be larger in the patient group compared to controls, although these differences did not quite reach significance (both $\mathrm{t}>1.3$ ).

\section{Discussion}

\section{Task-Switching in Controls}

The implications of the results of the control group will be discussed first to provide a framework within which to discuss findings in the schizophrenia group. Behaviorally, RT was faster on repeat than switch trials. Informatively cued trials had faster RT and less switch cost than noninformatively cued trials. This pattern of results is consistent with a large body of literature showing a reduction in RT and switch cost with increasing time for preparation (e.g. Karayanidis et al., 2003; Meiran, 2000; Rogers \& Monsell, 1995) and valid cue information (Jamadar et al., in press; Nicholson, Karayanidis, Davies \& Michie, 2006; Swainson et al., 2006).

Consistent with previous studies, cue-locked waveforms (Figure 2A) showed an early increase in posterior positivity for informatively relative to non-informatively cued trials (informativepositivity; see also Jamadar et al., in press) and a later increase in posterior positivity for informatively cued switch relative to repeat trials (switch-positivity; Goffaux et al., 2006; Karayanidis et al., 2003; Kieffaber \& Hetrick, 2005; Miniussi et al., 2005; Nicholson et al., 2005; Poulsen et al., 2005; Rushworth et al., 2002; 2005). Stimulus-locked ERPs (Figure 2B) showed an early onset posterior positivity for non-informatively vs. informatively cued trials and a later onset reduction in posterior positivity for informatively cued switch vs. repeat trials. This later effect is consistent with the switch-negativity reported previously (Goffaux et al., 2006; Karayanidis et al., 2003; Kieffaber \& Hetrick, 2005; Miniussi et al., 2005; Nicholson et al., 2005; Poulsen et al., 2005; Rushworth et al., $2002 ; 2005)$ and is associated with effort to overcome S-R priming or interference. Stimulus-locked waveforms showed no differentiation between non-informatively cued switch and repeat trials. While this finding is incompatible with previous evidence suggesting that when there is little or no opportunity to prepare for the next trial (e.g., RSI or CSI <150ms) stimulus-locked waveforms show an early switch-positivity followed by the switch-negativity (e.g., Karayanidis et al., 2003; Nicholson et al., 2005), it is consistent with results from another study using the same paradigm (Jamadar et al., 
in press, Experiment 2; see also non-informative condition in Swainson et al., 2006). Jamadar et al. (in press) suggested that the effect may reflect reduced facilitation of repeat trial processing following non-informative cues, resulting in repeat trials being treated like switch trials, at least at the level of cue and stimulus processing. Response-locked waveforms (Figure 2C) showed a large negativity for informatively vs. non-informatively cued trial . In informative trials, control participants are able to effectively prepare C-R rules in advance of the stimulus, and hence C-R rule implementation and response execution are easier to perform on informative than non-informative trials, where C-R rules can not be prepared in advance. Our previous work (Jamadar et al., in press) has shown that as C-R rule implementation and response execution become easier, the amplitude of the pre-response negativity becomes larger, consistent with a preparatory advantage in informative relative to noninformative trials.

During task-switching (informatively cued switch > repeat), controls activated a frontoparietal network encompassing the left SMA, left DLPFC and bilateral PPC similar to that found earlier with this paradigm (see Figure 3, Table 2; Jamadar et al., in press) as well as other task-switching paradigms (Braver et al., 2003; Brass \& von Cramon, 2004; Crone et al., 2005; Ruge et al., 2005). A similar frontoparietal network has been implicated in a range of cognitive behaviors, including cognitive preparation, goal-directed behavior, and detection and suppression of interference (Bunge et al., 2002; Egner \& Hirsch, 2005; Ridderinkof, van den Wildenberg, Segalowitz \& Carter, 2004). These findings are consistent with the DLPFC's role in attentional top-down signal biasing (Bunge et al., 2002; Egner \& Hirsch, 2005; Jamadar et al., in revision) and support the contention that the DLPFC achieves goal-directed behavior by maintaining task-relevant information. The findings are also compatible with the PPC's role in reconfiguring and updating task-set information immediately following a switch in task (Braver et al., 2003), possibly by activating and manipulating new S-R associations on switch relative to repeat trials (Andersen, 1987; Andersen \& Buneo, 2002; Bunge et al., 2002; Crone et al., 2005; Jamadar et al., in revision). In line with findings by Jamadar et al. (in revision), task-repetition (informatively cued repeat > switch) was associated with a single region of activity in the MTG, an area implicated in the retrieval of action semantics (Noppeney, Josephs, 
Kiebel, Friston \& Price, 2005), suggesting that this activity may reflect re-implementation of same C$\mathrm{R}$ rules as those used on the previous trial.

We found significant relationships between fMRI activation and both behavioral switch cost and cue-locked switch-positivity (Figures $5 \& 6$, Table 4). Specifically, informatively cued RT switch cost was related to activity in a distributed frontoparietal network that included FPC, VLPFC, PMv, PPC and posterior cingulate. In addition to its role in inhibition, the VLPFC is involved in forming associations between stimuli and action sequences (Passingham, Toni \& Rushworth, 2000; Ridderinkhof et al., 2004). The FPC is activated during formation of response-reinforcer contingencies guiding behavioral strategies to achieve task goals (Ridderinkhof et al., 2004). Premotor activation was more ventral to that observed previously (Jamadar et al., in revision), however this region is believed to be involved in preparing and executing movements, and is connected with more ventral regions of the PFC and PPC (Hoshi \& Tanji, 2006). This pattern of results is therefore consistent with the argument that residual RT switch cost is proportional to the effort required to activate and implement the new $\mathrm{C}-\mathrm{R}$ rule, rather than more generic preparation processes. The amplitude of the switch-positivity was associated with activity in the VLPFC, ACC and PPC. Activity in VLPFC/ACC suggests that switch-positivity amplitude may index cognitive control necessary to overcome interference from the competing task-set. ACC activation is associated with conflict detection (Botvinick, Braver, Barch, Carter \& Cohen, 2001) and signals the need to exert cognitive control (Botvinick et al., 2001; Kerns, Cohen, MacDonald, Cho, Stenger \& Carter, 2004; Liston et al., 2006; Luks et al., 2002). Given the role of the VLPFC in inhibitory mechanisms (Aron, Behrens, Smith, Frank \& Poldrack , 2007; Aron, 2007; Aron \& Poldrack, 2006; Jamadar et al., in revision), this suggests that the signal for cognitive control results in inhibition of the currently irrelevant task-set. This is consistent with ERP evidence that the switch-positivity indexes, at least in part, task-set inhibition during the preparatory interval (Karayanidis et al., 2009; Nicholson, Karayanidis, Davies \& Michie, 2006; see also Sinai, Goffaux \& Phillips, 2007).

In summary, in line with a large body of literature, task-switching resulted in slower RT on switch trials relative to repeat trials and on unprepared relative to prepared trials, as well as a larger 
switch cost on unprepared relative to prepared trials (Jamadar et al., in press; Karayanidis et al., 2003; Nicholson et al., 2005; Rogers \& Monsell, 1995; Meiran, Chorev \& Sapir, 2000; Swainson et al., 2006). The residual RT switch cost was associated with fMRI activity in a frontoparietal network suggestive of activation and implementation of the new C-R rule. This supports models of taskswitching that attribute residual switch cost to interference carried over from the previous trial or triggered by the stimulus itself (Allport \& Wylie, 2000; Wylie \& Allport, 2000). ERPs replicated a growing body of evidence showing a cue-locked switch-positivity and stimulus-locked switchnegativity (Goffaux et al., 2006; Karayanidis et al., 2003; Kieffaber \& Hetrick, 2005; Miniussi et al., 2005; Nicholson et al., 2005; Nicholson, Karayanidis, Davies \& Michie, 2006; Poulsen et al., 2005; Rushworth et al., 2002; 2005) as well as a cue-locked informative-positivity (Jamadar et al., in press; Swainson et al., 2006). The association between brain activation and both behavioral and ERP measures were consistent with our previous conclusion that the informative-positivity indexes goal activation, whereas the switch-positivity indexes C-R rule activation and that the latter process may include inhibition of the previously active, now irrelevant task-set (Jamadar et al., in press; Karayanidis et al., 2009).

The early part of the post-stimulus switch-negativity was correlated with task-switching activity in the FPC, whereas the later part was correlated with activity in the FPC, ACC, PM and PPC. This represents a much larger network of activation than that found in our previous study (Jamadar et al., in revision) where the amplitude of the differential switch-negativity was related to task-switching activity in the ACC only. However, note that in that study, the amplitude of the switch-negativity was much smaller than that found previously or reported here. The association between the early part of the differential switch-negativity and task-switching activity in the FPC, a region linked to top-down control of task-sets in task-switching (Sakai and Passingham, 2006) and higher-order control in a recent model of cognitive control (Koechlin \& Summerfield, 2008), suggests that C-R rule implementation, as indexed by the switch-negativity involves some level of top-down control. This result is therefore compatible with models of task-switching that propose a stimulus-driven control process in the post-stimulus interval (Rogers \& Monsell, 1995; Rubinstein et al., 2001). The 
association between the later part of the switch-negativity and ACC activation is compatible with models of task-switching which argue that post-stimulus processes related to detection and suppression of between-task interference contribute to the switch cost (Allport et al., 1994; Allport \& Wylie, 2000; Wylie \& Allport, 2000). Consistent with these models, task-switching related activity in the PM and PPC may reflect increased effort for response preparation and stimulus-specific C-R rule activation in the presence of conflict. Together, these results suggest the switch-negativity indexes multiple processes including top-down control and interference detection and are therefore consistent with multiple component models of task-switching which invoke both control and interference processes in the post-stimulus interval (e.g., Meiran, Chorev \& Sapir (2000).

\section{Task-Switching in Schizophrenia}

Consistent with previous findings in schizophrenia (Karayanidis et al., 2006; Kieffaber et al., 2006; Kieffaber et al., 2007; Meiran, Levine et al., 2000), while patients were overall slower in responding than controls, there were no group differences in RT switch cost or its reduction for informatively relative to non-informatively cued trials (Figure 1). The cue-locked informativepositivity and switch-positivity did not differ between patients and controls, suggesting that goal activation and C-R rule activation are intact in individuals with schizophrenia (Figure 2A). These findings are consistent with those reported by Kieffaber et al. (2007) using a cued task-switching paradigm but contrast with Karayanidis et al. (2006) who used an alternating runs paradigm.

Therefore, it would appear that patients can prepare effectively for an externally cued switch, but have difficulty preparing for an internally cued switch (see also Williams, Phillips, Bellgrove, Bradshaw, Bradshaw \& Pantelis, 2000). This finding is reminiscent of a specific deficit with internally cued as compared to externally cued switching in patients with Parkinsons's disease, a disorder associated with dopaminergic cell death in the substantia nigra (Werheid, Koch, Reichert \& Brass, 2007). In Karayanidis et al. (2006), patients showed intact switch-positivity at short preparation intervals, but no switch-positivity at long intervals. One possibility is that the representation of the previously active task-set dissipates more rapidly in schizophrenia. This would result in any repetition benefit being intact at short preparation intervals, but less effective at longer preparation intervals. As a result, 
patients would need to perform anticipatory reconfiguration for both switch and repeat trials, thereby eliminating the differential switch-positivity (Karayanidis et al., 2006). A deficit in maintaining attentional strategy over longer intervals in the absence of external cueing has been reported with different paradigms (Mathalon, Heinks, \& Ford, 2004; Michie, Fox, Ward, Catts \& McConaghy, 1990).

Stimulus-locked waveforms for non-informatively cued trials did not differ between schizophrenia and control groups (Figure 2B). On informatively cued trials, individuals with schizophrenia showed a much smaller LPC, a finding that is commonly reported in schizophrenia (Ford, 1999; Frodl, Meisenzahl, Muller, Holder, Jucker et al., 2002; Jeon \& Polich, 2003; Molina et al., 2005; Meisenzahl, Frodl, Muller, Schmitt, Gallinant et al., 2004; Olbrich, Maes, Valerius, Langosch \& Fiege, 2005; Weir, Fiaschi \& Machin, 1998), and may reflect a deficit in attentional allocation. Although, at first glance, this finding supports the argument that post-stimulus effects in task-switching reflect P300 modulation (e.g. Kieffaber \& Hetrick, 2005), note that the LPC of noninformative trials was not reduced in the schizophrenia group. Together with the fact that, in five groups of participants, we have not found a switch-negativity on non-informative trials with this paradigm (Jamadar et al., in press; current study), it would appear that, at least on non-informative trials, the LPC does not represent a P3b alone, but rather a number of overlapping positivities.

Note that, for the schizophrenia group, the reduction in informatively cued LPC was accompanied by elimination of the differential switch-negativity as well as a frontocentral negative shift for both informatively cued stimulus-locked waveforms. If the stimulus-locked switch-negativity reflects greater S-R interference and the resulting difficulty of C-R rule implementation on prepared switch vs. repeat trials, this broad negative shift for both prepared switch and prepared repeat trials in patients may reflect greater interference or allocation of resources to overcome this interference affecting both trial types. The reduced negativity in the pre-response complex for informatively cued trials in patients further suggests that informatively cued trials show similar pre-response processing to that of unprepared non-informatively cued trials (Figure 2C). As previously mentioned, an increase in negativity in the pre-response complex is believed to index the ease of C-R rule implementation 
and response execution (Jamadar et al., in press). While controls showed a large difference between informative and noninformative trials, patients did not, largely due to a reduction in the amplitude of informative trials. This may suggest that patients did not prepare C-R rules as effective as controls, however cue-locked results argue against this conclusion. Rather, it is seems that C-R rule implementation and response execution are more difficult for patients than controls due to increased between-task interference in patients, possibly more so for noninformative repeat trials. This conclusion is consistent with the increased ACC activity for repeat relative to switch trials observed in fMRI (see below). Together, we argue that the stimulus-locked and response-locked findings are consistent with greater difficulty of C-R rule implementation in patients than controls.

\section{fMRI Correlates of Task-Switching in Schizophrenia}

The fMRI correlates of task-switching in schizophrenia were examined in the informatively cued condition, thereby representing task-switching with anticipatory preparation. The task-switching (informatively cued switch > repeat) contrast showed activation in the left DLPFC and left PPC for both controls and patients (Figure 3A), suggesting an intact frontoparietal network in switching. This is somewhat surprising, given that the hypofrontality hypothesis of schizophrenia is supported by many studies showing reduced DLPFC activity across a range of tasks (Barch, 2005; Cannon et al., 2005; Meyer-Lindenberg et al., 2002; Molina et al., 2005; Morey et al., 2005), reduced DLPFC grey matter volume (Antonova et al., 2004), as well as altered PPC function and structure (Quintana et al., 2003; Torrey, 2007; Zhou et al., 2006). Quintana et al. (2003) argue that DLPFC hypofunction in schizophrenia only occurs when other areas of the frontoparietal network (i.e., PPC) are able to support task-specific processing. However when the PPC is unable to support this processing, this results in PFC and PPC hyperactivity as observed here (Figure 3A bottom). In the current context, this pattern of results may be interpreted as indicating that increased DLPFC and PPC activity in patients normalizes preparatory processing leading to intact switch-positivity and early stimulus-locked processing. This would suggest that patients may have overcome DLPFC deficits by employing a compensatory mechanism which allowed them to achieve the same behavioral outcome as controls. The ERP findings suggest that this occurred at a cost in efficiency of C-R rule implementation, 
resulting in overall increase in RT. Therefore, with cued task-switching, increased frontoparietal activation seems to compensate for any differences in preparatory processes and to adjust C-R rule implementation processes so as to eliminate differences in task-switching performance.

Interestingly, the SMA proper, an area involved in initiation and selection of a motor program (Picard \& Strick, 1996), was activated for the task-switching contrast in controls but not in patients. The SMA is involved in retrieving established motor programs rather than motor execution (Picard \& Strick, 1996). While pre-SMA activation is high when learning a new motor sequence, SMA proper activation increases as motor programs are well established and become automatic (Picard \& Strick, 1996). The fact that controls but not patients showed activity in this region suggests that the substantial practice on the task prior to testing resulted in establishment of motor programs in controls, but that patients benefited less from this practice. This is consistent with group differences in response-locked ERPs suggesting of a disruption of C-R rule implementation in schizophrenia. While the SMA proper but not pre-SMA activation in controls appears to contradict TMS evidence that functional integrity of the pre-SMA is crucial for efficient task-switching (Rushworth, Hadland, Paus $\&$ Sipila 2002), our finding may be related to the fact that participants were highly practiced on the task whereas Rushworth's were not.

Even more pronounced group differences were obtained when examining areas activated more on repeat than on switch trials (informatively cued repeat > switch; Figure 3B). Specifically, patients but not controls showed activation in a broadly distributed frontoparietal network including DLPFC/FPC, DMPFC, ACC, primary motor cortex, PHG, PPC and posterior cingulate. Interestingly, the level of activation in DLPFC, ACC, PPC and posterior cingulate in patients was similar to that observed for the switch>repeat contrast in controls (see also Figure 4). That patients activated similar regions in task-repetition as controls did for task-switching suggests that patients found task-repetition as difficult as task-switching, a conclusion that is compatible with greater pre-response interference (response-locked ERPs) during performance of a repeat relative to switch trials in schizophrenia. The DMPFC activity is in a region implicated in pre-response conflict (Ridderinkhof et al., 2004), and the PHG activity may reflect resolution of conflict arising from competing goals for behavior 
(McNaughton, 2006). Given that 1) ERP differences between groups were only evident late in the stimulus-locked ERPs and in response-locked ERPs, 2) a deficit in maintaining attentional strategy over longer intervals has been reported in schizophrenia previously (Karayanidis et al., 2006; Mathalon et al., 2004; Michie et al., 1990), 3) repetition bias may dissipate more quickly in patients (current data; Karayanidis et al., 2006), and 4) the bivalent stimuli used here did not include taskidentifying information, activity in these areas is likely to reflect an attempt to overcome between-task interference on repeat trials. On switch trials, neither group can benefit from repetition priming bias to facilitate stimulus or response selection, and both groups need to consistently apply a selective bias filter to select the correct stimulus and response-set ${ }^{3}$. However, on repeat trials, patients seem to benefit less from repetition priming bias and to employ strategies to overcome pre-response conflict. This seems to lead to more effortful processing, but little effect on overt behavior, perhaps as a result of having completed substantial practice prior to ERP or fMRI recordings. It would be interesting to examine performance over the learning period to examine how the refinement of this process develops.

The schizophrenia group showed the same relationship between RT switch cost and activity in the PMd and bilateral PPC as controls, although the premotor activity was more dorsal to that observed in the control group (Figure 5). Like the PMv, the PMd is involved in selecting and planning motor behaviour, but is also involved in integrating information to formulate a motor program for the intended action (Hoshi \& Tanji, 2006). Patients showed bilateral PPC hyperactivity relative to controls. This may reflect increased effort to maintain the C-R mappings needed to implement a response (Bunge et al., 2002; Jamadar et al., in revision) and is consistent with greater difficulty of C$\mathrm{R}$ rule implementation in patients.

In patients, the cue-locked switch-positivity was also related to activity in the bilateral PPC, but not in the VLPFC or ACC (Figure 6). Therefore, although patients successfully activated C-R rules prior to stimulus onset, they may not have effectively suppressed the irrelevant task-set during

\footnotetext{
${ }^{3}$ The use of $100 \%$ incongruent stimuli most likely exacerbated this effect. To our knowledge, although taskswitching performance has been examined with both univalent and bivalent stimuli in schizophrenia (e.g. Karayanidis et al., 2006; Kieffaber et al., 2007), no study has examined the effects of stimulus-crosstalk in taskswitching in schizophrenia.
} 
the preparatory interval and this may have increased post-stimulus cross-task interference. There is substantial evidence for impaired conflict/error detection in schizophrenia (Barch, 2005; Laurens et al., 2003) as well as evidence of ACC structural abnormalities (Benes, 2000; Bouras, Kovari, Hof, Riederer \& Giannakopoulos, 2001) and reduced ACC activity in a variety of tasks that involve high interference and conflict, such as the Tower of London task (Andreasen, Rezai, Alliger, Swayze, Flaum et al., 1992), no-go response inhibition (Rubia, Russell, Bullmore, Soni, Brammer, et al., 2001) and WCST (Meyer-Lindenberg et al., 2002).

The early component of the stimulus-locked switch-negativity was related to activity in bilateral ACC and PM and the later component with FPC and PPC. Patients did not show the early activity in the FPC suggesting impaired top-down control of C-R rule implementation in schizophrenia. Activity in the ACC was much earlier and of much greater amplitude in the patients relative to controls, consistent with increased interference during $\mathrm{C}-\mathrm{R}$ rule implementation in schizophrenia. The later activity in the FPC and PPC may reflect an attempt by the FPC to increase activation of C-R rules held in the PPC to compensate for the increased susceptibility to betweentasks interference, thereby achieving the same behavioural outcome as controls. Thus these results are entirely compatible with the argument that individuals with schizophrenia show intact anticipatory preparation but impaired C-R rule implementation, but are able to compensate for these difficulties to achieve the same behavioural outcome as controls.

\section{Summary and Conclusions}

We replicated previous studies showing intact task-switching performance in schizophrenia (Karayanidis et al., 2006; Kieffaber et al., 2006; Kieffaber et al., 2007; Meiran, Levine et al., 2000) with a cued-trials paradigm and bivalent stimuli. ERPs and ERP/fMRI correlations suggested that anticipatory preparation was intact in schizophrenia. Differences later in the stimulus-locked epoch and in response-locked waveforms suggest that patients had difficulty in implementing C-R rules. The difficulty in implementing C-R rules appears to be overcome by increasing the bias of C-R rules held in the PPC. fMRI data suggested that patients hyperactivate the frontoparietal network implicated in task-switching in compenstion for structural and functional deficits of this system (Quintana et al., 
2003), and a similar compensatory mechanism appears to be employed on repeat trials. Given that patients' performance was largely similar to that of controls, it seems that this compensatory mechansism was successful. 


\section{References}

Allport, A., Styles, E. A., \& Hsieh, S. (1994). Shifting intentional set: Exploring the dynamic control of tasks. In C. Umilta \& M. Moscovitvh (Eds.), Attention and Performance XV (pp.421-452). Cambridge, MA: MIT Press.

Allport, D. A., \& Wylie, G. (2000). Task-switching, stimulus response bindings, and negative priming. In S. Monsell \& J. Driver (Eds.), Attention and Performance XVIII (pp. 35-70). Cambridge, MA: MIT Press.

Altmann, E.M (2004). The preparation effect in task switching: Carryover of SOA. Memory \& Cognition, 32, 153-163.

Andersen, R. A. (1987). The role of the inferior parietal lobule in spatial perception and visual-motor integration. In F. Plum; V.B. Mountcastle; and S.R. Geiger (Eds). The Handbook of Physiology. Section I: The Nervous System Volume V. Higher Functions of the Brain Part 2, pp. 483-518. Bethesda, MD., American Physiological Society.

Andersen, R.A., \& Buneo, C.A. (2002). Intentional maps in posterior parietal cortex. Annual Reviews of the Neurosciences, 25, 189-220.

Andersson, J.L.R., Hutton, C., Ashburner, J., Turner, R., \& Friston, K. (2001). Modeling geometric deformations in EPI time series. NeuroImage, 13, 903-919.

Andreasen, N.C. (1984a). Scale for the assessment of negative symptoms (SANS). University of Iowa: Iowa.

Andreasen, N.C. (1984b). Scale for the assessment of positive symptoms (SAPS). University of Iowa: Iowa.

Andreasen, N.C., Rezai, K., Alliger, R., Swayze, V.W., Flaum, M, et al. (1992). Hypofrontality in neuroleptic-naive patients and in patients with chronic schizophrenia: assessment with xenon 133 single-photon emission computed tomography and the Tower of London. Archives of General Psychiatry, 49, 943-958

Antonova, E., Sharma, T., Morris, R., \& Kumari, V. (2004). The relationship between brain structure and neurocognition in schizophrenia: a selective review. Schizophrenia Research, 70, 117-145.

Aron, A.R. (2007). Neural basis of inhibition in cognitive control. The Neuroscientist, 13, 214-228.

Aron, A.R., Behrens, T.E., Smith, S., Frank, M.J., \& Poldrack, R.A. (2007). Triangulating a cognitive control network using diffusion-weighted magnetic resonance imaging (MRI) and functional MRI. The Journal of Neuroscience, 27, 3743-3752.

Aron, A.R., \& Poldrack, R.A. (2006). Cortical and subcortical contributions to stop signal response inhibition: Role of the subthalamic nucleus. The Journal of Neuroscience, 26, 2424-2433.

Barbato, A. (1998). Schizophrenia and Public Health. World Health Organisation: Geneva.

Barch, D.M. (2005). The cognitive neuroscience of schizophrenia. Annual Review of Clinical Psychology, 1, 321-353. 
Benes FM. (2000). Emerging principles of altered neural circuitry in schizophrenia. Brain Research Reviews, 31, 251-69

Bonilha, L., Molna, C., Horner, M.D., Anderson, B., Forster, L., George, M.S., \& Nahas, Z. (2008). Neurocognitive deficits and prefrontal cortical atrophy in patients with schizophrenia. Schizophrenia Research, 101, 142-151.

Botvinick, M. M., Braver, T. S., Barch, D. M., Carter, C. S., \& Cohen, J. D. (2001). Conflict monitoring and cognitive control. Psychological Review, 108, 624-652.

Brass, M., von Cramon, D. Y. (2004). Decomposing components of task preparation with functional magnetic resonance imaging. Journal of Cognitive Neuroscience, 16(4), 609-620.

Braver, T.S., Reynolds, J.R., \& Donaldson, D.I. (2003). Neural mechanisms of transient and sustained cognitive control during task switching. Neuron, 39, 713-726.

Brett, M., Anton, J-L., Valabregue, R. \& Poline, J-B. (2002). Region of interest analysis using the MarsBar toolbox for SPM99. Presented at the 8th International Conference on Functional Mapping of the Human Brain, June 2-6, 2002, Sendai, Japan.

Brown R.G. \& Marsden C.D. (1988). Internal vs. external cues and the control of attention in Parkinson's disease. Brain, 111, 323-45.

Bunge, S.A., Hazeltine, E., Scanlon, M.D., Rosen, A.C. \& Gabrieli, J.D.E (2002). Dissociable contributions of prefrontal and parietal cortices to response selection. NeuroImage, 17, 15621571.

Cannon, T.D., Glahn, D.C., Kim, J., Van ERP, T.G.M., Karlsgodt, K. et al. (2005). Dorsolateral prefrontal cortex activity during maintenance and manipulation of information in working memory in patients with schizophrenia. Archives of General Psychiatry, 62, 1071-1080.

Castle D.J., Jablensky A., McGrath J.J., Carr V., Morgan V., Waterreus A., et al. (2006): The diagnostic interview for psychoses (DIP): Development, reliability and applications. Psychological Medicine, 36, 69-80.

Coles, M.G.H., Bernstein, P.S., Fournier, L. (1995) Where did you go wrong? Errors, partial errors, and the nature of information processing. Acta Psychologica, 90, 129-144.

Crone, E.A., Wendelken, C., Donohue, S.E., \& Bunge, S.A. (2006). Neural evidence for dissociable components of task-switching. Cerebral Cortex, 16, 475-486.

Damasio, H. (2005). Human Brain Anatomy in Computerized Images. New York: Oxford University Press.

Damen E.J.P. \& Brunia C.H.M. (1994). Is a stimulus conveying task-relevant information a sufficient condition to elicit a stimulus-preceding negativity? Psychophysiology,31, 129-39.

Danckert, J., Saoud, M., \& Maruff, P. (2004). Attention, motor control and motor imagery in schizophrenia: implications for the role of the parietal cortex. Schizophrenia Research, 70, 241261. 
Egner, T., \& Hirsch, J. (2005). Cognitive control mechanisms resolve conflict through cortical amplification of task-relevant information. Nature Neuroscience, 8, 1784-1790.

Everett, J., Lavoie, K., Gagnon, J-F., \& Gosselin, N. (2001). Performance of patients with schizophrenia on the Wisconsin Card Sorting Test (WCST). Journal of Psychiatry and Neuroscience, 25, 123-130.

Ford JM. (1999) Schizophrenia: the broken P300 and beyond. Psychophysiology, 36, 667-682.

Forstmann, B.U., van den Wildenberg, W., \& Ridderinkhof, K.R. (2008). Neural mechanisms, temporal dynamics, and individual differences in interference control. Journal of Cognitive Neuroscience, 20, 1854-1865

Frodl, T., Meisenzahl, E.M., Muller, D., Holder, J., Juckel, G., et al. (2002). P300 subcomponents and clinical symptoms in schizophrenia. International Journal of Psychophysiology, 43, 237-246.

Fulham, W.R. (2005). EEG Display (Version 4.10) [Computer software]. Newcastle, Australia.

Goffaux, P., Phillips, N.A., Sinai, M., \& Pushkar, D. (2006). Behavioural and electrophysiological measures of task switching during single and mixed-task conditions. Biological Psychology, $72,278-290$.

Goldberg, T.E., Weinberger, D.R., Berman, K.F., Pliskin, N.H. \& Podd, M.H. (1987). Further evidence for dementia of the prefrontal type in schizophrenia? A controlled study of teaching in the Wisconsin Card Sorting Test. Archives of General Psychiatry, 44, 1008-1014.

Green MF, Kern RS, Braff DL, Mintz J. (2000). Neurocognitive deficits and functional outcome in schizophrenia: Are we measuring the "right stuff"? Schizophrenia Bulletin, 26, 119- 136

Guthrie, D., \& Buchwald, J. S. (1991). Significance testing of difference potentials. Psychophysiology, 28, 240-244.

Horovitz, S.G., Rossion, B., Skudlarski, P. \& Gore, J.C. (2004). Parametric design and correlational analyses help integrating fMRI and electrophysiological data during face processing. NeuroImage, 22, 1587-1595.

Horovitz, S.G., Skudlarski, P. \& Gore, J.C. (2002). Correlations and dissociations between BOLD signal and P300 amplitude in an auditory oddball task: a parametric approach to combining fMRI and ERP. Magnetic Resonance Imaging, 20, 319-325.

Hoshi, E., \& Tanji, J. (2007). Distinctions between dorsal and ventral premotor areas: Anatomical connectivity and functional properties. Current Opinion in Neurobiology, 17, 234-242.

Jamadar, S., Hughes, M., Fulham, R., Michie, P.T. \& Karayanidis, F. (in revision). The spatial and temporal dynamics of anticipatory preparation and response inhibition. NeuroImage.

Jamadar, S., Nicholson, R., Michie P \& Karayanidis, F. (in press). No-go/go and other sequence effects in task-switching modulate response preparedness and repetition priming processes. Psychophysiology.

Jeon, Y-W, \& Polich, J. (2003). Meta-analysis of P300 and schizophrenia: patients, paradigms, and practical implications. Psychophysiology, 40, 684-701. 
Josephs, O., Turner, R., \& Friston, K.J. (1997). Event-related fMRI. Human Brain Mapping, 5, 243248.

Karayanidis, F., Coltheart, M., Michie, P. T., Murphy, K. (2003). Electrophysiological correlates of anticipatory and post-stimulus components of task-switching. Psychophysiology, 40, 329-348.

Karayanidis, F., Nicholson, R., Meem, L., Schall, U., Fulham, R., \& Michie, P. T. (2006). Switching between univalent task-sets in schizophrenia: ERP evidence of an anticipatory task-set reconfiguration deficit. Clinical Neurophysiology, 117, 2172-2190.

Kerns JG, Cohen JD, MacDonaldAW, Johnson MK, Stenger VA, Aizenstein H, Carter CS (2005): Decreased conflict and error-related activity in the anterior cingulate cortex in subjects with schizophrenia. American Journal of Psychiatry, 162, 1833-1839.

Kerns, J.G., Cohen, J.D., MacDonald, A.W., Cho, R.Y., Stenger, V.A. \& Carter, C.S. (2004). Anterior cingulate conflict monitoring predicts adjustments in control. Science, 303, 1023-1026.

Kerns, J.G., Nuechterlein, K.H., Braver, T.S. \& Barch, D.M. (2008). Executive functioning component mechanisms and schizophrenia. Biological Psychiatry, 64, 26-33.

Koechlin, E., \& Summerfield, C. (2007). An information theoretical approach to prefrontal executive function. Trends in Cognitive Sciences, 11, 229-235.

Kieffaber, P.D., \& Hetrick, W.P. (2005). Event-related potential correlates of task switching and switch costs. Psychophysiology, 42, 56-71.

Kieffaber, P.D., Kappenman, E.S., Bodkins,M., Shekhar, A., O'Donnell, B.F., Hetrick, W.P. (2006). Switch and maintenance of task set in schizophrenia. Schizophrenia Research 84 (2-3), 345358.

Kieffaber, P.D., O’Donnel, B.F., Shekhar, A., \& Hetrick, W.P. (2007). Event related brain potential evidence for preserved attentional set switching in schizophrenia. Schizophrenia Research, 93, 355-365.

Koch, I., \& Allport, A. (2006). Cue-based preparation and stimulus-based priming of tasks in task switching. Memory \& Cognition, 34, 433-444.

Koch, I., Ruge, H., Brass, M., Rubin, O., Meiran, N, \& Prinz, W. (2003). Equivalence of cognitive processes in brain imaging and behavioral studies: evidence from task switching. NeuroImage, 20, 572-577.

Lancaster, J.L., Woldorff, M.G., Parsons, L.M., Liotti, M., Freitas, C.S., Rainey, L., et al. (2000). Automated Talairach atlas labels for functional brain mapping. Human Brain Mapping, 10, 120-131.

Laurens, K.R., Ngan, E.T.C., Bates, A.T., Kiehl, K.A., \& Liddle, P.F. (2003). Rostral anterior cingulate cortex dysfunction during error processing in schizophrenia. Brain, 126, 610-622.

Li, C.S. (2004). Do schizophrenia patients make more perseverative than non-perseverative errors on the Wisconsin Card Sorting Test? A meta-analytic study. Psychiatry Research, 129, 179-190. 
Liston, C., Matalon, S., Hare, T.A., Davidson, M.C., Casey, B.J. (2006). Anterior cingulate and posterior parietal cortices are sensitive to dissociable forms of conflict in a task-switching paradigm. Neuron, 50, 643-653.

Logan, G.D., \& Bundesen, C. (2003). Clever homunculus: Is there an endogenous act of control in the explicit task-cuing procedure? Journal of Experimental Psychology: Human Perception and Performance, 29, 575-599.

Luks, T.L., Simpon, G.V., Feiwell, R.J., \& Miller, W.L. (2002). Evidence for anterior cingulate cortex involvement in monitoring preparatory attentional set. NeuroImage, 17, 792-802.

Luck, S. (2005). An Introduction to the Event-Related Potential Technique. MIT Press.

Mamah, D., wang, L., Barch, D., de Erausquin, G.A., Gado, M., \& Csernansky, J.G. (2007). Structural analysis of the basal ganglia in schizophrenia. Schizophrenia Research, 89, 59-71.

Mathalon, D.H., Heinks, T., Ford, J.M. (2004). Selective attention in schizophrenia: sparing and loss of executive control. American Journal of Psychiatry, 161, 872-81.

Mayka, M.A., Corcos, D.M., Leurgans, S.E., \& Vaillancourt, D.E. (2006). Three-dimensional locations and boundaries of motor and premotor cortices as defined by functional brain imaging: A meta-analysis. NeuroImage, 31, 1453-1474.

Mayr, U., \& Keele, S.W. (2000). Changing internal constraints on action: The role of backward inhibition. Journal of Experimental Psychology: General, 129, 4-26.

Mazaika, P., Whitfield, S., \& Cooper, J.C. (2005). Detection and repair of transient artifacts in fMRI data. NeuroImage, 26-S1, S36.

McCallum W.C. \& Walter W.G. (1968). The effects of attention and distraction on the contingent negative variation in normal and neurotic subjects. Electroencephalography and Clinical Neurophysiology, 25, 319-29.

McNaughton, N. (2006). The role of the subiculum within the behavioural inhibition system. Behavioural Brain Research, 174, 232-250.

Meiran, N. (2000). Reconfiguration of stimulus task sets and response task sets during task switching. In S. Monsell \& J. Driver (Eds.), Attention and Performance XVIII (pp. 377-399). Cambridge: MIT Press.

Meiran, N., Chorev, Z., \& Sapir, A. (2000). Component Processes in Task Switching. Cognitive Psychology, 41, 211-253.

Meiran N., Levine J., Meiran N., \& Henik A. (2000) Task set switching in schizophrenia. Neuropsychology, 14, 471-82.

Meisenzahl, E.M., Frodl, T., Muller, D., Schmitt, G., Gallinant, J., Ztezsche, T., et al. (2004). Superior temporal gyrus and P300 in schizophrenia: a combined ERP/structural magnetic resonance imaging investigation. Journal of Psychiatric Research, 38, 153-162. 
Meyer-Lindenberg, A., Poline, J-B., Koh, P.D., Holt, J.L., Egan, M.F., Weinberger, D.R., \& Berman, K.F. (2001). Evidence for abnormal cortical function connectivity during working memory in schizophrenia. American Journal of Psychiatry, 158, 1809-1917.

Michie, P.T., Fox, A.M., Ward, P.B., Catts, S.V. \& McConaghy, N. (1990). Event-related potential indices of selective attention and cortical lateralization in schizophrenia. Psychophysiology, 27, 209-27.

Miniussi, C., Marzi, C.A., \& Nobre, A.C. (2005). Modulation of brain activity by selective task sets observed using event-related potentials. Neuropsychologia, 43, 1514-1528.

Molina, V., Sanz, J., Munoz, F., Casado, P., Hinoiosa, J.A., Sarramea, F., \& Martin-Loeches, M. (2005). Dorsolateral prefrontal cortex contribution to abnormalities of the P300 component of the event-related potential in schizophrenia. Psychiatry Research: Neuroimaging, 140, 17-26

Monsell, S. (2003). Task switching. Trends in Cognitive Sciences, 7, 134-140.

Morey, R.A., Inan, S., Mitchell, T.V., Perkins, D.O., Lieberman, J.A., \& Belger, A. (2005). Imaging frontostriatal function in ultra-high risk, early, and chronic schizophrenia during executive processing. Archives of General Psychiatry, 62, 254-262.

Nelson, H.E. (1982) National Adult Reading Test: Test Manual. Windsor, UK: NFER

Neuhaus, A., Koehler, S., Opgen-Rhein, C., Urbanek, C., Hahn, E., \& Dettling, M. (2007). Selective anterior cingulate cortex deficit during conflict solution in schizophrenia: an event-related potential study. Journal of Psychiatric Research, 41, 635-644.

Nicholson, R., Karayanidis, F., Bumak, E., Poboka, D., \& Michie, P.T. (2006). ERPs dissociate the effects of switching task sets and task cues. Brain Research, 1095, 107-123.

Nicholson, R., Karayanidis, F., Davies, A., \& Michie, P.T. (2006). Components of task-set reconfiguration: Differential effects of 'switch-to' and 'switch-away' cues. Brain Research, 1121, 160-176.

Nicholson, R., Karayanidis, F., Poboka, D., Heathcote, A., \& Michie, P. (2005). Electrophysiological correlates of anticipatory task-switching processes. Psychophysiology, 42, 540-554.

Noppeney, U., Josephs, O., Kiebel, S., Friston, K.J. \& Price, C.J. (2005). Action selectivity in parietal and temporal cortex. Cognitive Brain Research, 25, 641-649.

Olbrich, H.M., Maes, H., Valerius, G., Langosch, J.M., \& Feige, B. (2005). Event-related potential correlates selectively reflect cognitive dysfunction in schizophrenia. Journal of Neural Transmission, 283-295.

Pantelis, C., Barber, F.Z., Barnes, T.R.E., Nelson, H.E., Owen, A.M., \& Robbins, T.W. (1999). Comparison of set-shifting ability in patients with chronic schizophrenia and frontal lobe damage. Schizophrenia Research, 37, 251-270. 
Passingham, R. E., Toni, I., \& Rushworth, M. F. S. (2000). Specialisation within the prefrontal cortex: The ventral prefrontal cortex and associative learning. Experimental Brain Research, 133, 103113.

Picard, N. \& Strick, P.L. (1996). Motor areas of the medial wall: a review of their location and functional activation. Cerebral Cortex, 6, 342-353.

Poulsen, C., Luu, P., Davey, C., \& Tucker, D. M. (2005). Dynamics of task sets: Evidence from dense-array event-related potentials. Cognitive Brain Research, 24, 133-154.

Prentice, K.J., Gold, J.M., \& Buchanan, R.W. (in press). The Wisconsin Card Sorting impairment in schizophrenia is evident in the first four trials. Schizophrenia Research.

Pritchard, W.S. (1986). Cognitive event-related potential correlates of schizophrenia. Psychological Bulletin, 100, 43-66.

Quintana, J., Wong, T., Ortiz-Portillo, E., Kovalik, E., Davidson, T., Marder, S.R., et al. (2003). Prefrontal-posterior parietal networks in schizophrenia: primary dysfunctions and secondary compensations. Biological Psychiatry, 53, 12-24.

Reuter, B., Herzog, E., Endrass, T., \& Kathmann, N. (2006). Brain potentials indicate poor preparation for action in schizophrenia. Psychophysiology, 43, 604-611.

Ridderinkhof, K.R., van den Wildenberg, W.P.M., Segalowitz, S.J., \& Carter, C.S. (2004). Neurocognitive mechanisms in cognitive control: The role of prefrontal cortex in action selection, response inhibition, performance monitoring, and reward-based learning. Brain and Cognition, 56, 129-140.

Rogers, R. D., \& Monsell, S. (1995). Costs of a predictable switch between simple cognitive tasks. Journal of Experimental Psychology, 124, 207 - 231.

Rubia, K., Russell, T., Overmeyer, S., Brammer, M., Bullmore, E., Sharma, T., et al. (2001). Mapping motor inhibition: conjunctive brain activations across different versions of go/no-go and stop tasks. NeuroImage, 13, 250-261.

Rubinstein, J. S., Meyer, D. E., \& Evans, E. (2001). Executive control of cognitive processes in task switching. Journal of Experimental Psychology: Human Perception and Performance, 27, $763-$ 797.

Ruge, H., Brass, M., Koch, I., Rubin, O., Meiran, N., \& von Cramon, D.Y. (2005). Advance preparation and stimulus-induced interference in cued task switching: Further insights from BOLD fMRI. Neuropsychologia, 43, 340-355.

Rusch, N., Spoletini, I., Wilke, M., Bria, P., Di Paola, M., Di Iulio, F., et al. (2007). Prefrontalthalamic-cerebellar gray matter networks and executive functioning in schizophrenia. Schizophrenia Research, 93, 79-89. 
Rusch, N., van Elst, L.T., Valerius, G., Buchert, M., Thiel, T., Ebert, D., et al. (2008). Neurochemical and structural correlates of executive dysfunction in schizophrenia. Schizophrenia Research, 99, 155-163.

Rushworth, M.F.S., Hadland, K.A., Paus, T., \& Sipila, P.K. (2002). Role of the human medial frontal cortex in task-switching: a combined fMRI and TMS study. Journal of Neurophysiology, 87, 2577-2592.

Rushworth, M. F. S., Passingham, R. E., \& Nobre, A. C. (2002). Components of switching intentional set. Journal of Cognitive Neuroscience, 14, 1139-1150.

Rushworth, M. F. S., Passingham, R. E., \& Nobre, A. C. (2005). Components of attentional setswitching. Experimental Psychology, 52, 83-98.

Sakai, K., \& Passingham, R.E. (2006). Prefrontal set activity predicts rule-specific neural processing during subsequent cognitive performance. The Journal of Neuroscience, 26, 1211-1218.

Semlitsch, H. V., Anderer, P., Schuster, P., \& Presslich, O. (1986). A solution for reliable and valid reduction of ocular artefacts. Psychophysiology, 23, 695-703.

Sinai, M., Goffaux, P., \& Phillips, N.A. (2007). Cue- versus response-locked processes in backward inhibition: Evidence from ERPs. Psychophysiology, 44, 596-609.

Smith, G.L., Large, M.M., Kavanagh, D.J., Karayanidis, F., Barrett, N.A., Michie, P.T. et al. (1998). Further evidences for a deficit in switching attention in schizophrenia. Journal of Abnormal Psychology, 107, 390-398.

Sohn, M., Ursu, S., Anderson, J.R., Stenger, V.A., \& Carter, C.S. (2000). The role of prefrontal cortex and posterior parietal cortex in task-switching. Proceedings of the National Academy of Sciences, 97, 13448-13453.

Stratta, P., Mancini, F., Mattei, P., Daneluzzo, E., Casacchia, M., Rossi, A., 1997. Association between striatal reduction and poor Wisconsin card sorting test performance in patients with schizophrenia. Biological Psychiatry 42, 816-820.

Swainson, R., Jackson, S.R. \& Jackson, G.M. (2006). Using advance information in dynamic cognitive control: An ERP study of task-switching. Brain Research, 1105, 61-72.

Talairach, J. \& Tournox, P. (1988). Co-planar Stereotaxic Atlas of the Human Brain. New York: Thieme Medical Publishers.

Torrey, E.F. (2007). Schizophrenia and the inferior parietal lobule. Schizophrenia Research, 97, 215225.

Vasey, M. W., \& Thayer, J. F. (1987). The continuing problem of false positives in repeated measures ANOVA in psychophysiology: A multivariate solution. Psychophysiology, 24, 479-486.

Weinberger D.R., Berman K.F., Suddath R., \& Torrey E.F. (1992). Evidence of dysfunction of a prefrontal-limbic network in schizophrenia: a magnetic resonance imaging and regional 
cerebral blood flow study of discordant monozygotic twins. American Journal of Psychiatry, $149,890-897$

Weir, N., Fiaschi, K., Machin, D., (1998). The distribution and latency of the auditory P300 in schizophrenia and depression. Schizophrenia Research, 31, 151- 158.

Werheid, K., Koch, I., Reichert, K., \& Brass, M. (2007). Impaired self-initiated task-preparation during task switching in Parkinson's Disease. Neuropsychologia, 45, 273-281.

Williams S.B.K., Phillips J.G., Bellgrove M., Bradshaw J.L., Bradshaw J.A., \& Pantelis C. (2000). Use of advance information in patients with schizophrenia. Journal of Experimental and Clinical Neuropsychology, 22, 472-82.

Wylie, G., \& Allport, A. (2000). Task switching and the measurement of 'switch costs'. Psychological Research, 63, 212-233.

Wylie, G.R., Javitt, D.C., \& Foxe, J.J. (2006). Jumping the gun: Is effective preparation contingent upon anticipatory activation in task-relevant neural circuitry? Cerebral Cortex, 16, 394-404.

Yeung, N., Nystrom, L.E., Aronson, J.A., \& Cohen, J.D. (2006). Between-task competition and cognitive control in task-switching. The Journal of Neuroscience, 26, 1429-1438.

Zetzsche, T., Preuss, U., Frodl, T., Watz, D., Schmitt, G., Koutsouleris, N., et al. (2007). In-vivo topography of structural alterations of the anterior cingulate in patients with schizophrenia: new findings and comparison with the literature. Schizophrenia Research, 96, 34-45.

Zhou, S-Y., Suzuki, M., Takahashi, T., Hagino, H., Kawasaki, Y., Matsui, M., et al. (2007). Parietal lobe volume deficits in schizophrenia spectrum disorders. Schizophrenia Research, 89, 35-48. 


\section{FIGURE LEGENDS}

Figure 1: Behavioral results for the ERP (left) and fMRI (right) sessions. A: Number of errors; B: RT; C: RT switch cost, for each trial type for informatively cued (ERP and fMRI) and non-informatively cued (ERP only) trials. Abbreviations: Inf: informatively cued trials; Non-inf: non-informatively cued trials

Figure 2: Cue-locked (A), stimulus-locked (B) and response-locked (C) ERP waveforms for informatively cued (black thin) and non-informatively cued (gray thick) trials. Scalp topographies are depicted for the epochs used in mean amplitude analyses (gray bars in Pz plots). Negative is plotted up.

Figure 3: Task-switching (switch > repeat) activity and region-of-interest analysis for regions that were activated for both groups in this contrast. ROIs were defined as an $8 \mathrm{~mm}^{3}$ box around the peak of activity. Abbreviations: L: left; R: right; ACC: anterior cingulate cortex; DLPFC: dorsolateral prefrontal cortex; FPC: frontopolar cortex; IPL: inferior parietal lobule; MFG: middle frontal gyrus; MedFG: medial frontal gyrus; PHG: parahippocampal gyrus; PPC: posterior parietal cortex; SFG: superior frontal gyrus.

Figure 4: Task-repetition (switch > repeat) activity for control (A) and schizophrenia (B) groups. C. Areas differentially activated for schizophrenia vs. control group in task-repetition contrast (repeat > switch). Plots show regions of interest outcomes. ROIs were defined as an $8 \mathrm{~mm}^{3}$ box around the peak of activity. As this contrast is subtractive in nature, positive contrast values reflect regions activated by the schizophrenia group to a greater extent than controls during task-repetition. Negative contrast values reflect regions activated by the control group to a greater extent than the schizophrenia group during task-switching. Asterisks indicate significant deviance from baseline. Abbreviations: see Figure 3 legend

Figure 5: Multiple regression analysis of task-switching contrast (switch > repeat) with informatively cued RT switch cost. Scatterplots show the correlation between each variable and the mean contrast value extracted from ROIs defined as an $8 \mathrm{~mm}^{3}$ box around the peak of activity and partial correlation coefficients. Bar graph shows region-of-interest analysis at regions activated by both groups. Abbreviations: see Figure 3 legend.

Figure 6: Multiple regression analysis of task-switching contrast (switch > repeat) with mean amplitude of switch-positivity (500-600ms). Scatterplots show the correlation between each variable and the mean contrast value extracted from ROIs defined as an $8 \mathrm{~mm}^{3}$ box around the peak of activity and partial correlation coefficients. Bar graph shows region-of-interest analysis defined as an $8 \mathrm{~mm}^{3}$ box around the peak of activity of a common region activated by both groups. Abbreviations: see Figure 3 legend.

Figure 7: Multiple regression analysis of task-switching contrast (switch > repeat) with mean amplitude of switch-negativity over 300-400ms (red) and 500-600ms (blue) for each group. Scatterplots show the correlation between each variable and the mean contrast value extracted from ROIs defined as $8 \mathrm{~mm} 3$ boxes around the peak of activity and partial correlation coefficients. Bar graph shows ROI analysis for regions of common activation between the groups. Regions highlighted with an asterisk are regions that showed temporal activation differences. Abbreviations: see Figure 3 legend. 
FIGURE 1

ERP Session

CONTROL SCHIZOPHRENIA
fMRI Session

CONTROL SCHIZOPHRENIA

\section{A. Errors}
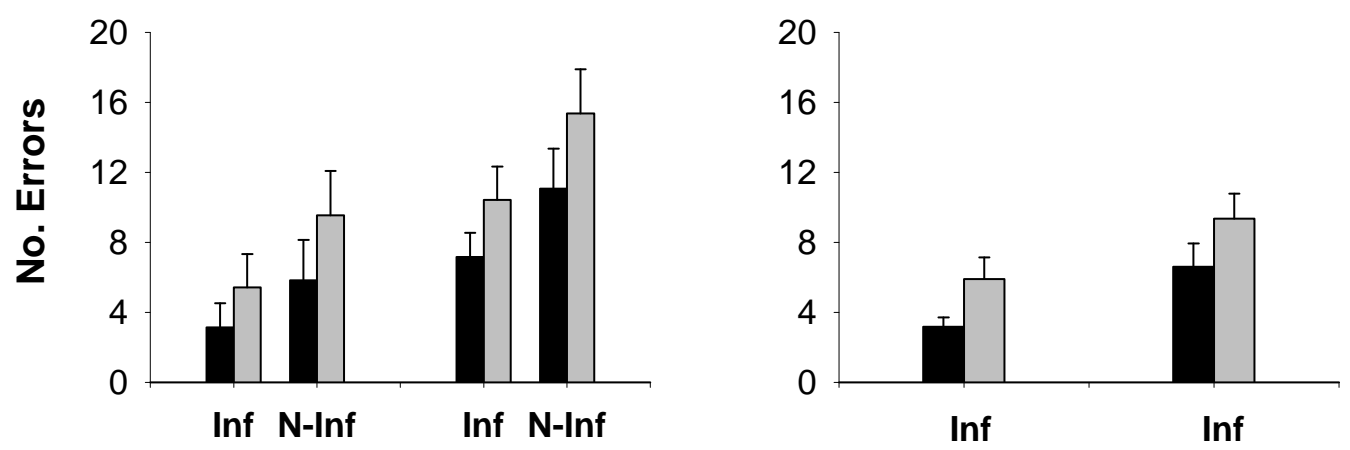

B. Reaction Time


C. RT Switch Cost
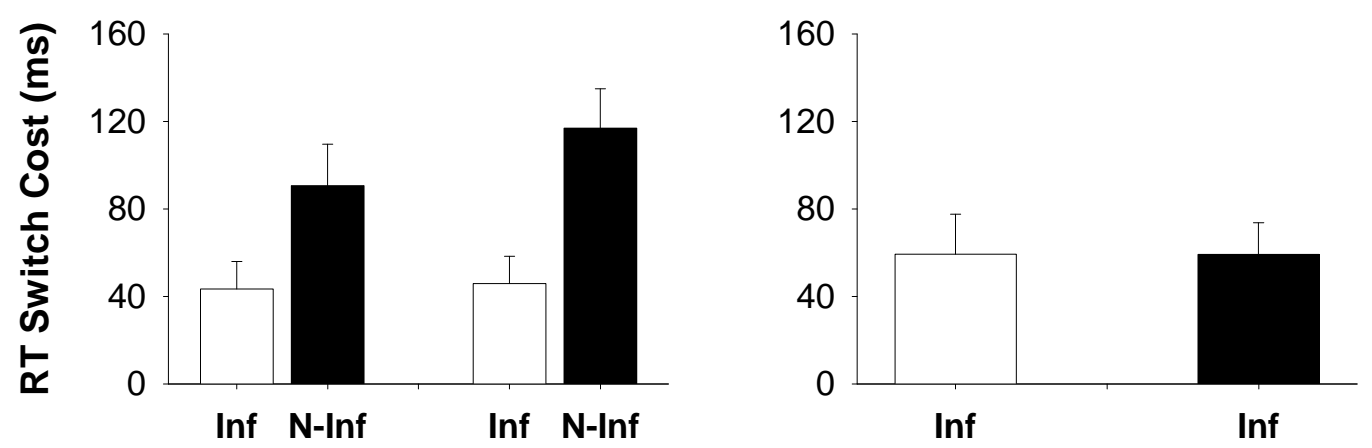


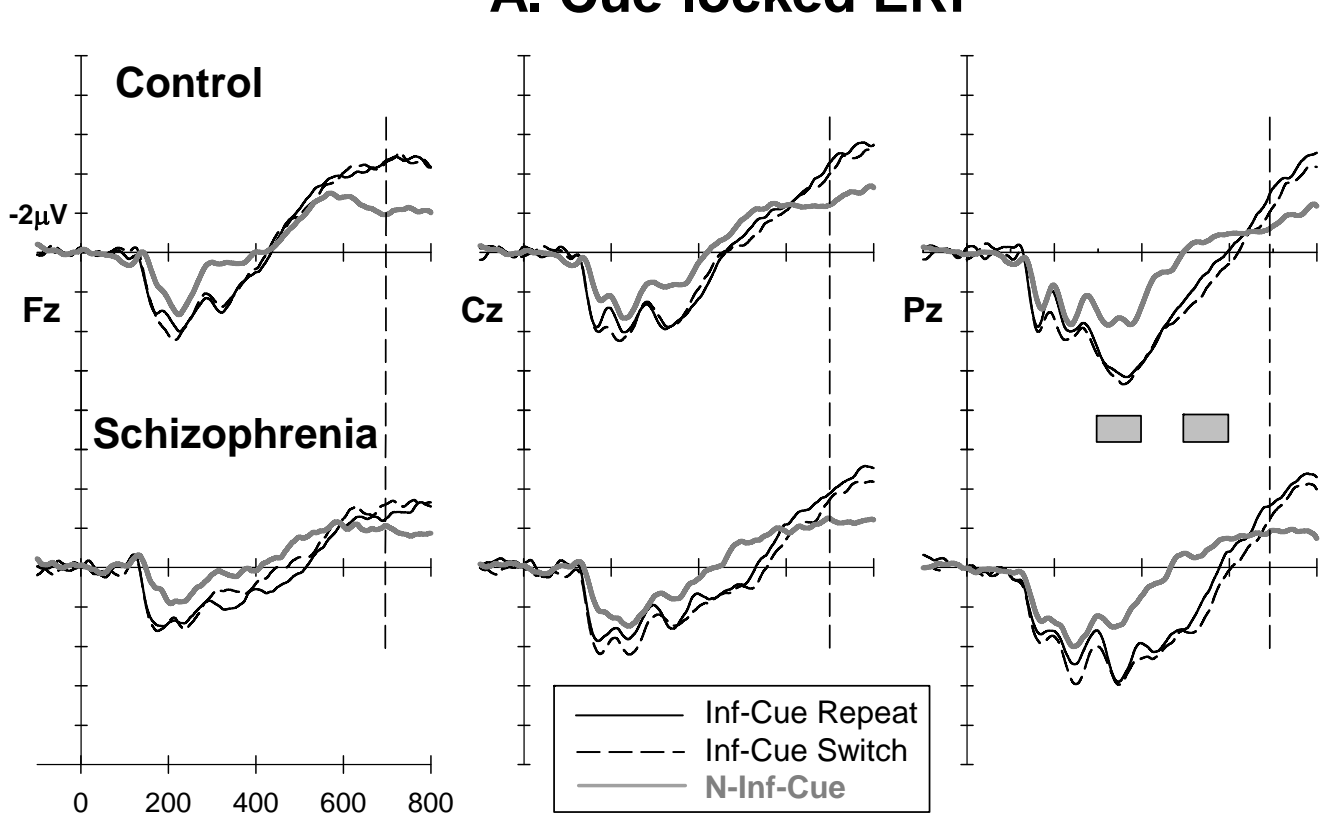

$$
\begin{array}{lc}
\text { Inf }- \text { NInf } & \text { Inf Swt - Rpt } \\
300-400 \mathrm{~ms} & 500-600 \mathrm{~ms}
\end{array}
$$
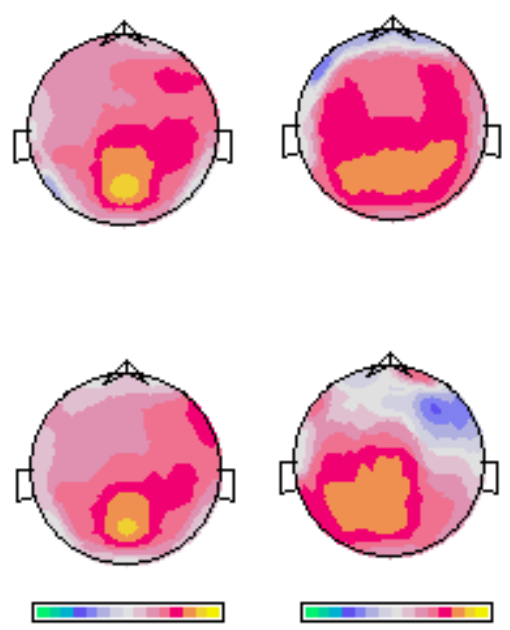

$-3.8 \mu \mathrm{V}+3.8 \mu \mathrm{V}-1.5 \mu \mathrm{V}+1.5 \mu \mathrm{V}$

\section{B. Stimulus-locked ERP}
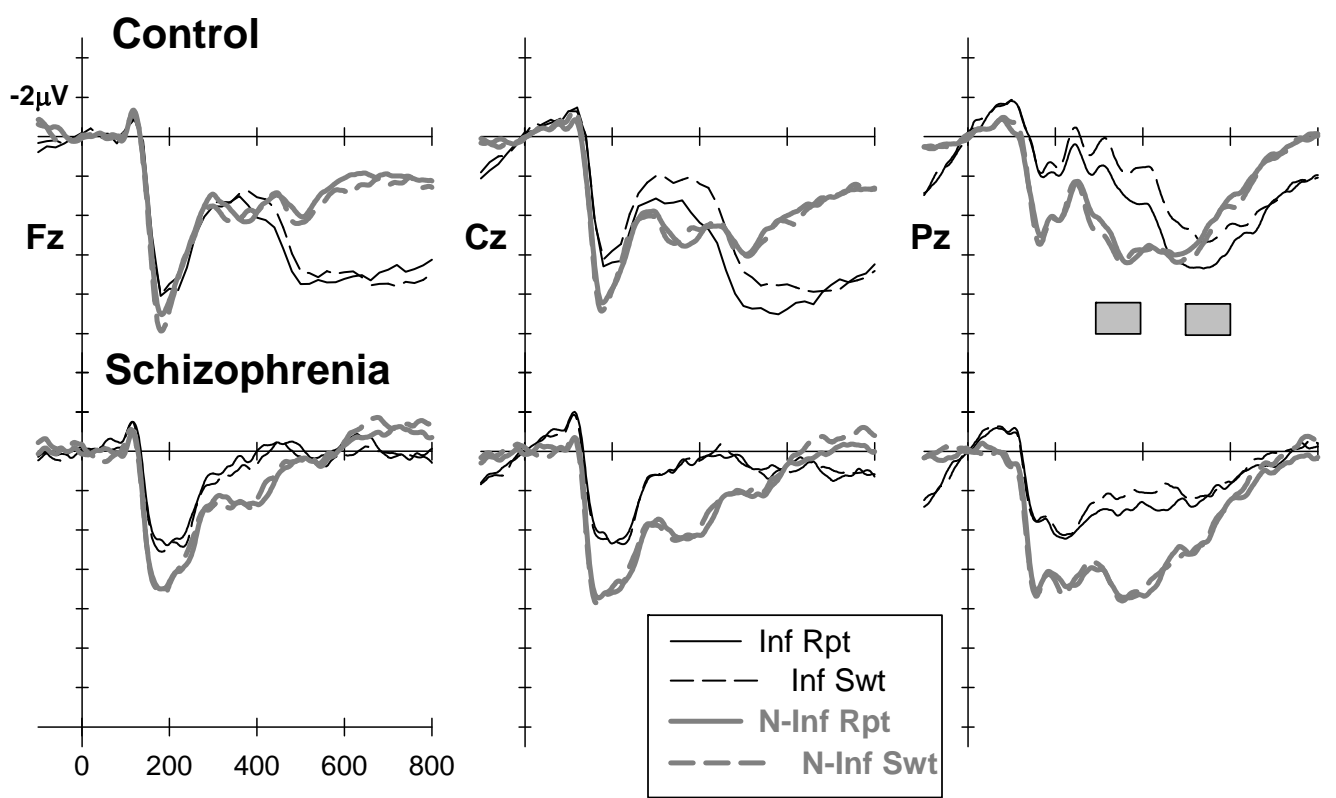

Inf Swt - Rpt Inf Swt - Rpt 300-400ms 500-600ms
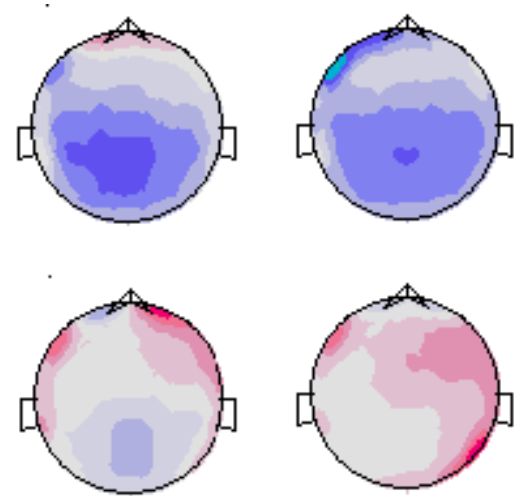

\section{Response-locked ERP}


Inf - Ninf -550 to $-450 \mathrm{~ms}$



\section{Switch > Repeat}

\section{Control Group}
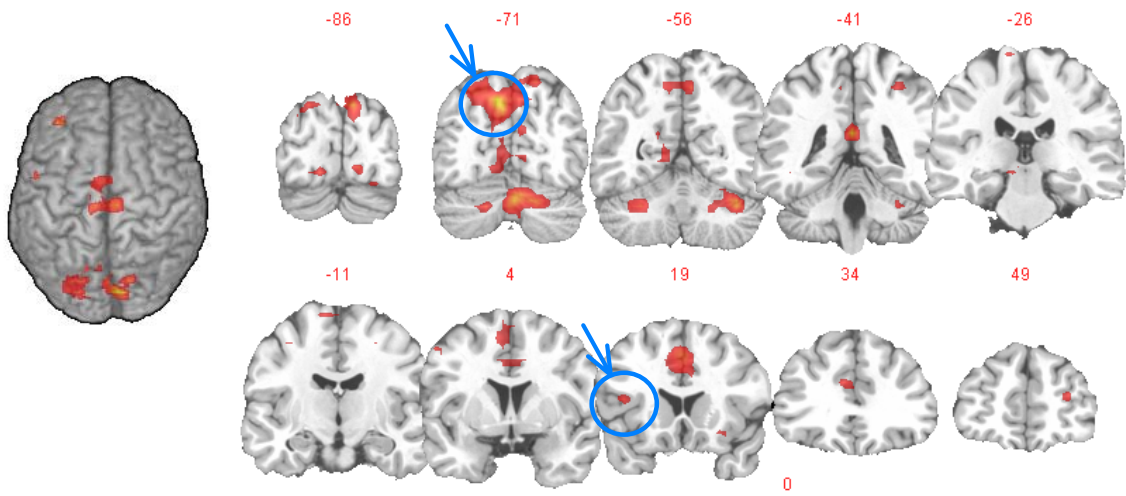

\section{Schizophrenia Group}
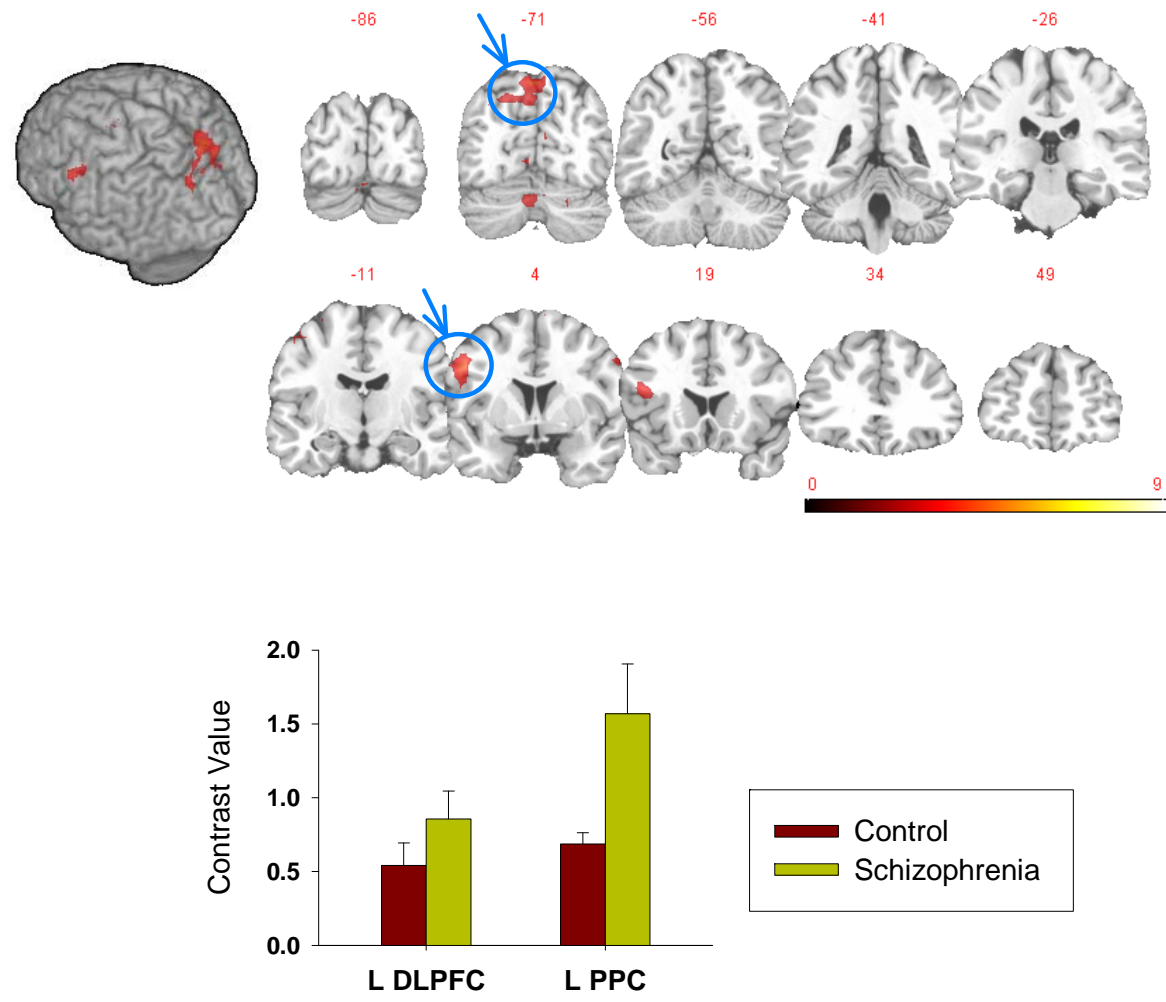


\section{Repeat $>$ Switch}

\section{A. Control Group}
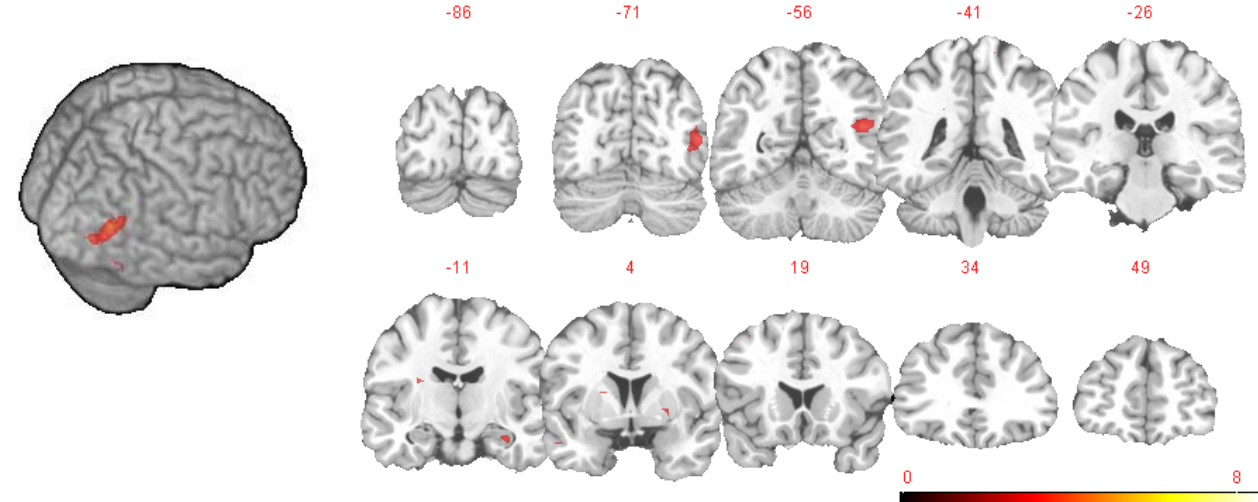

B. Schizophrenia Group
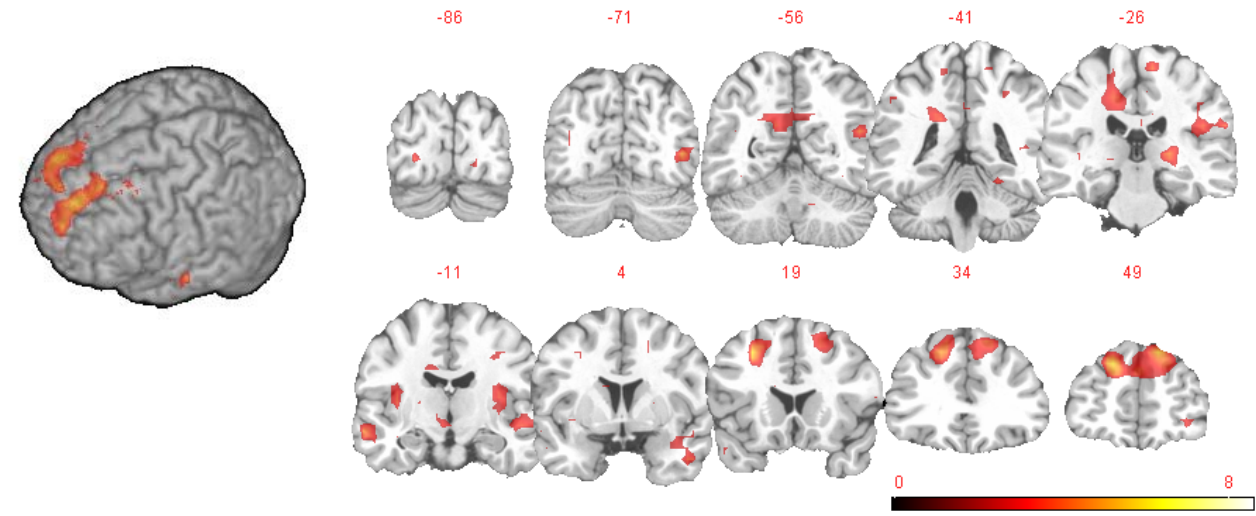

C. Schizophrenia vs. Control
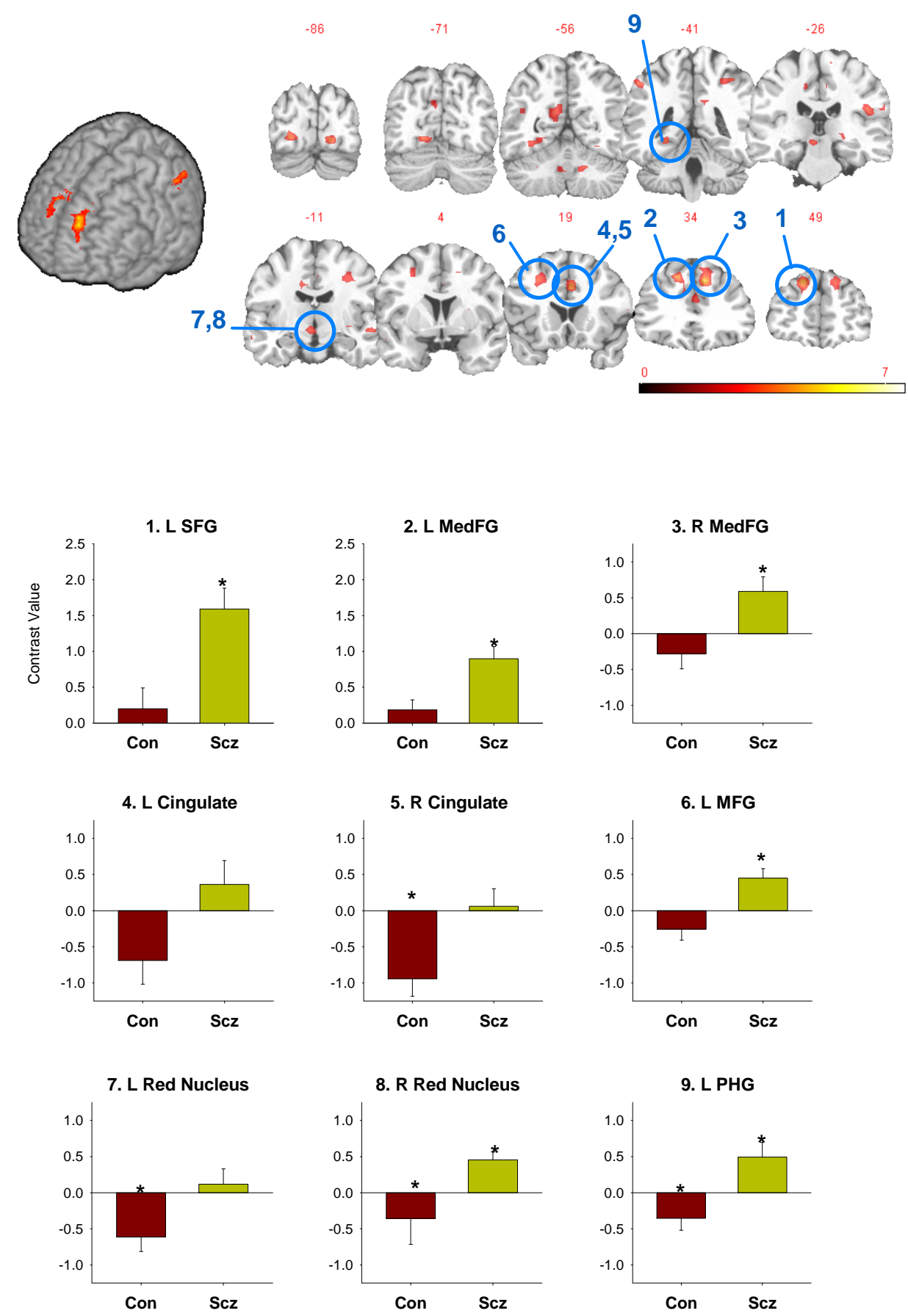


\section{Switch > Repeat \& Switch Cost}

\section{Control}
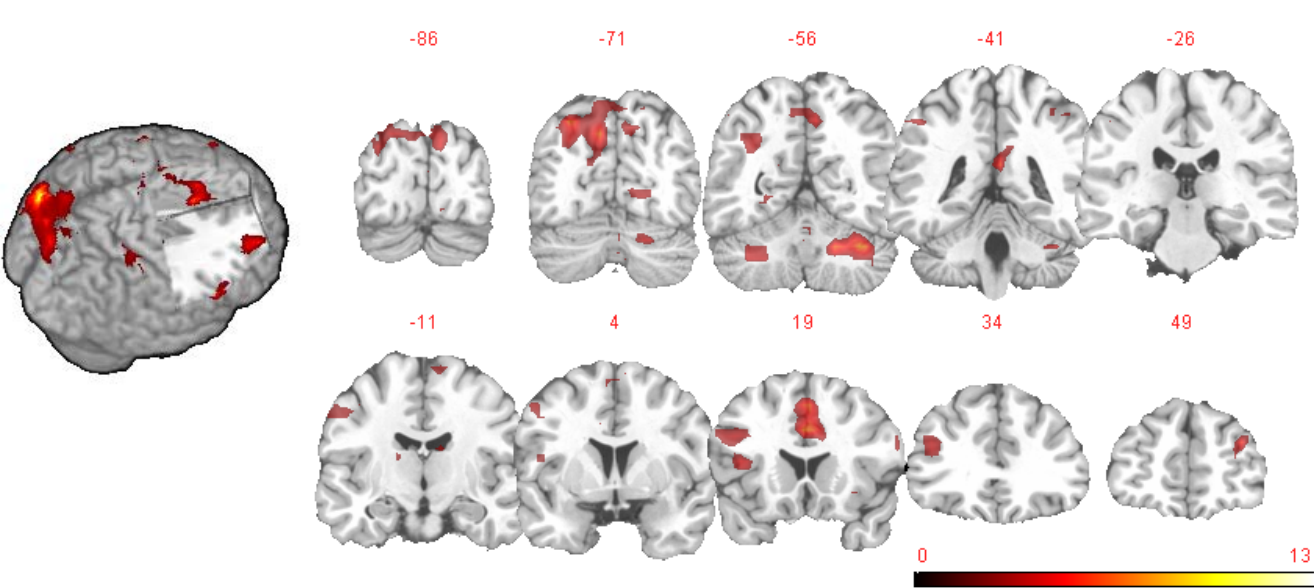
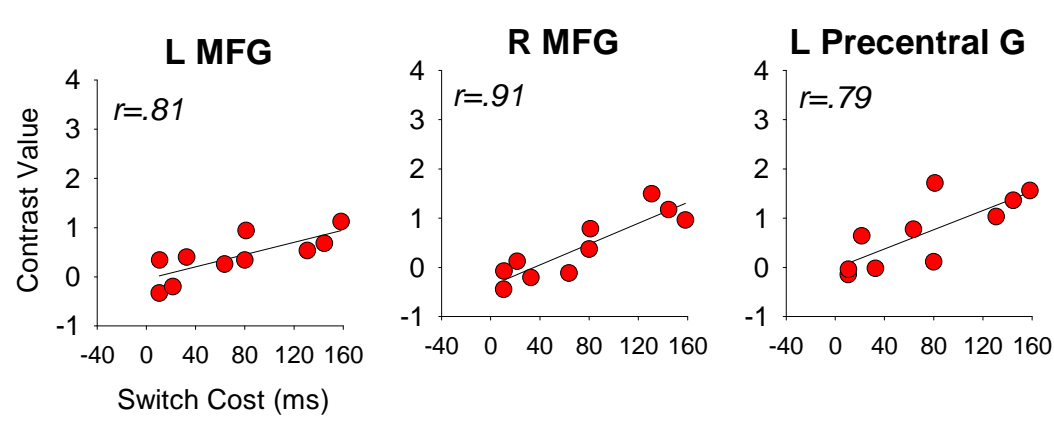

FIGURE 5



\section{Schizophrenia}
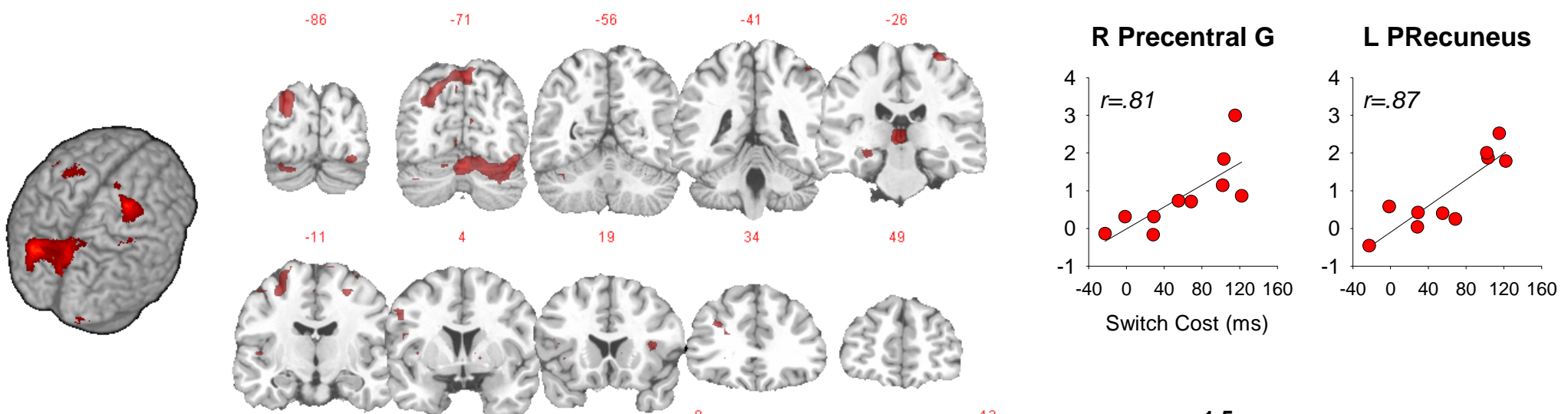

R PRecuneus

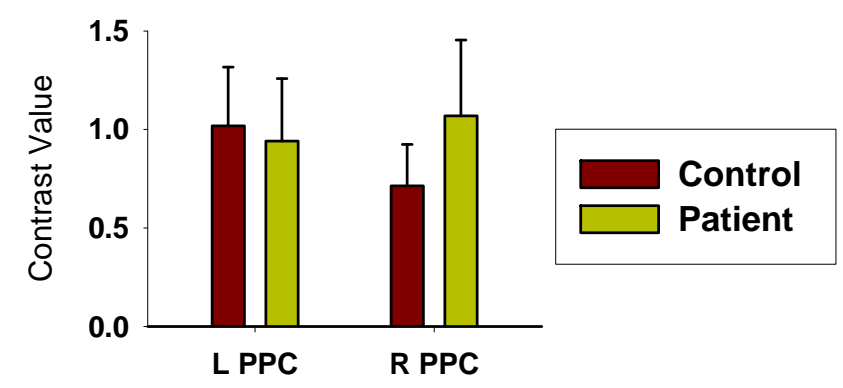


FIGURE 6

\section{Switch > Repeat \& Switch-Positivity}

\section{Control}
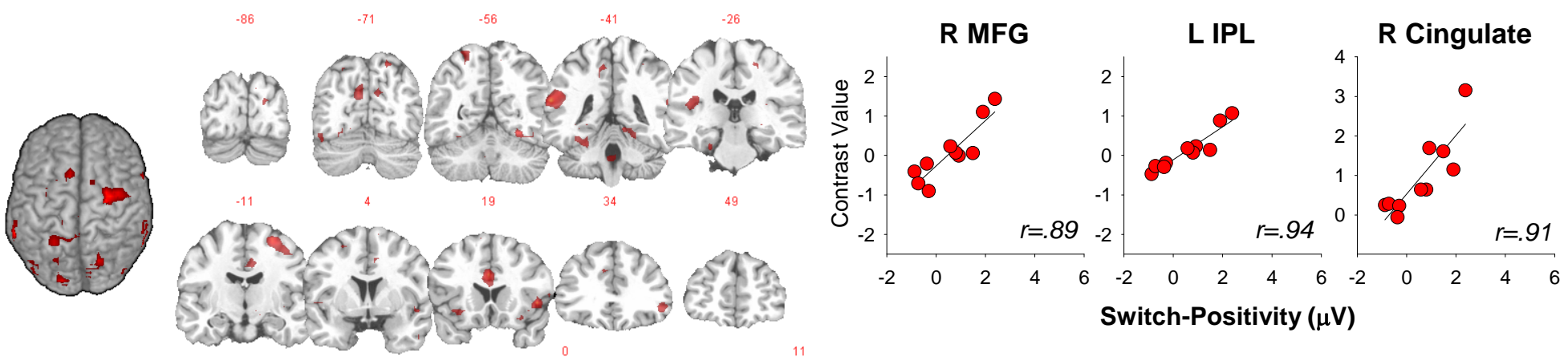

\section{Schizophrenia}
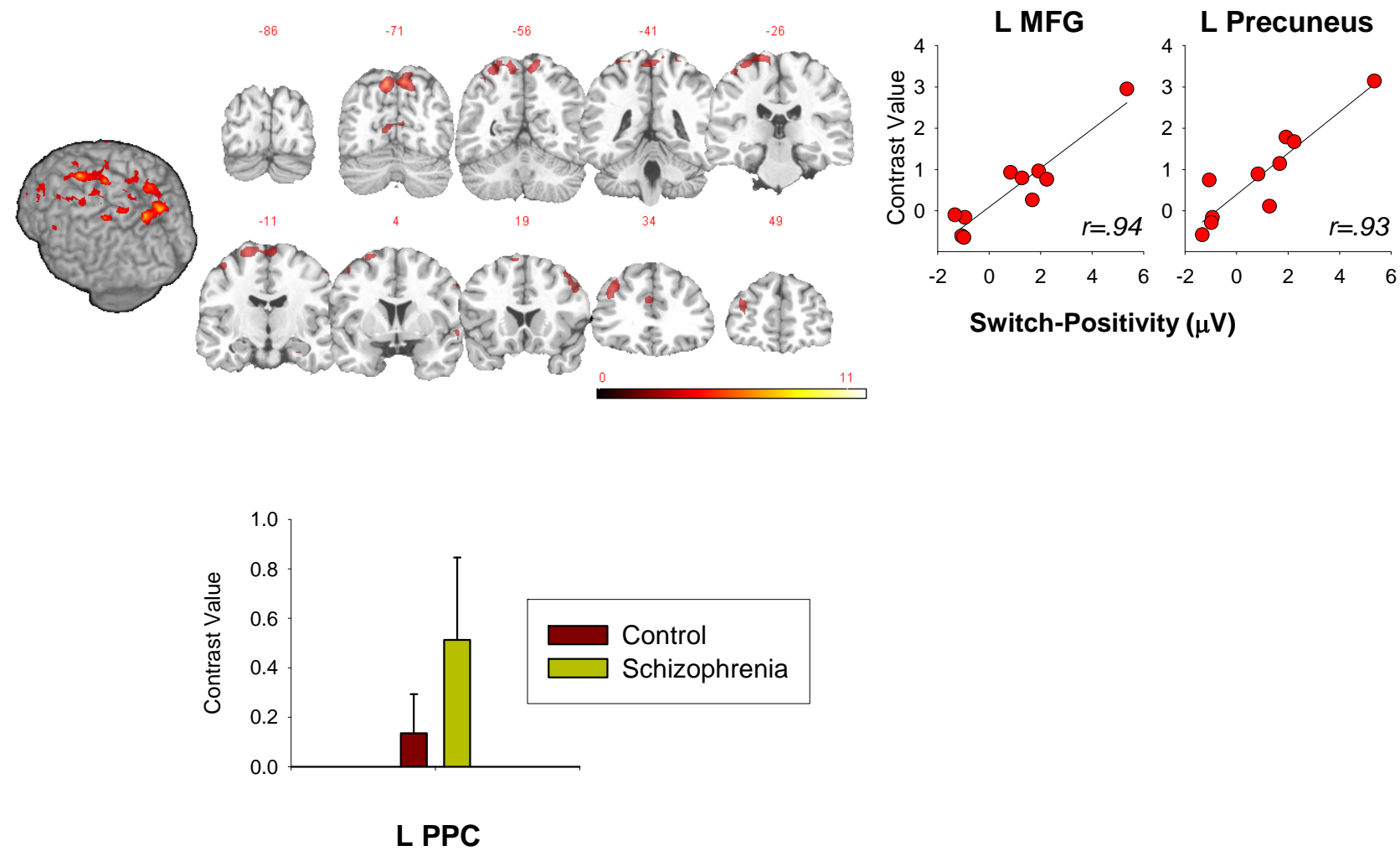


\section{Switch > Repeat \& Switch-Negativity}

\section{Control}
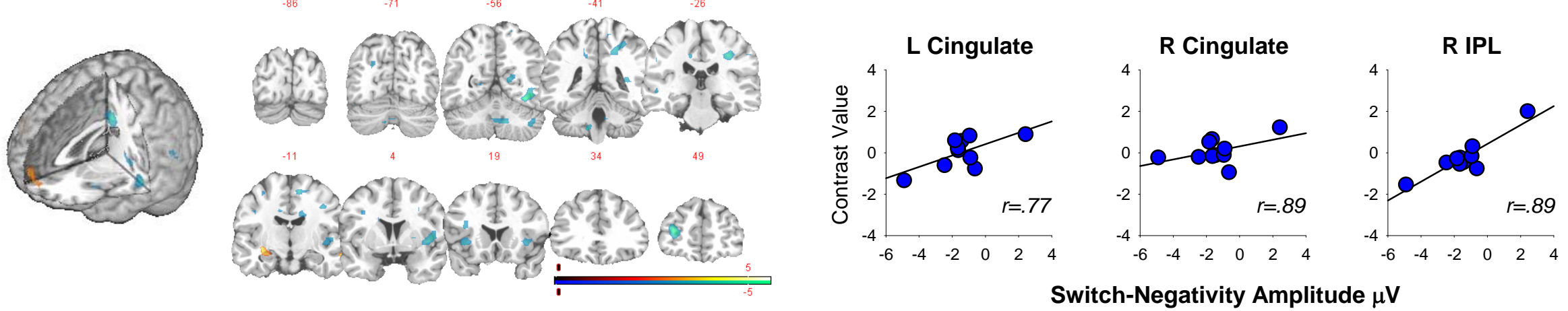

Switch-Negativity Amplitude $\mu \mathrm{V}$

\section{Schizophrenia}
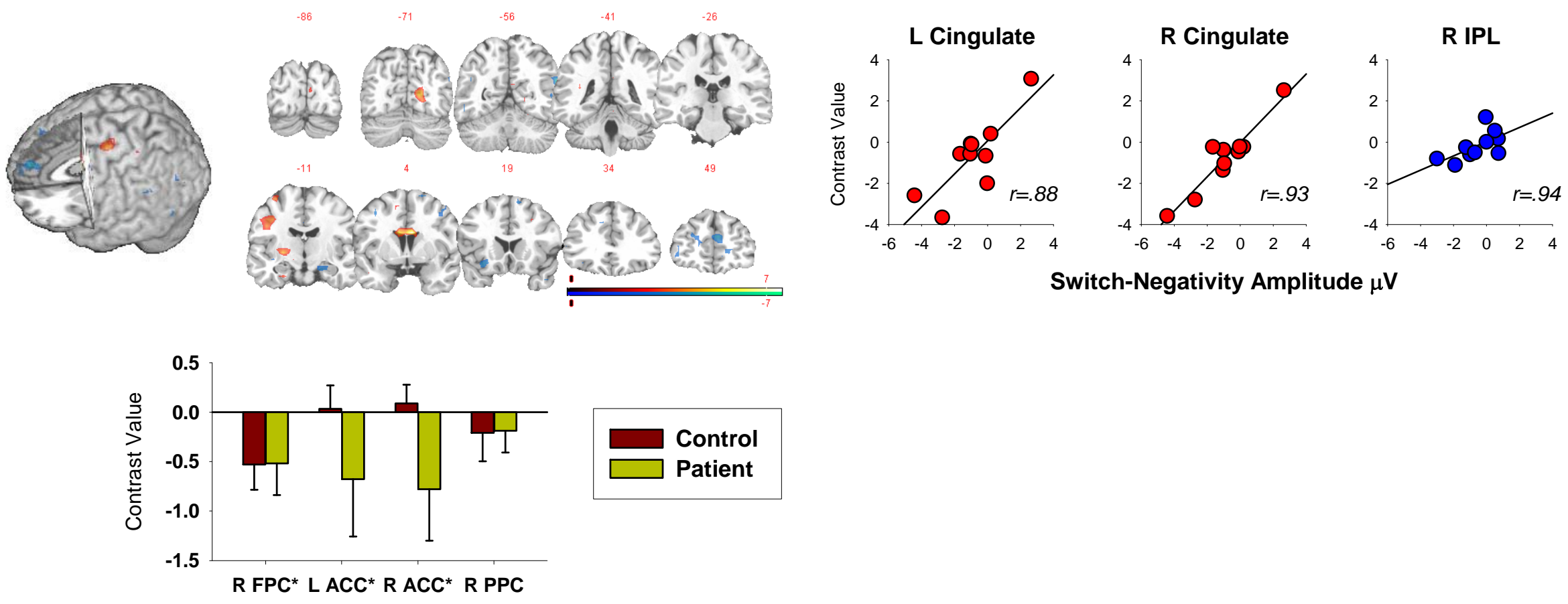

Control Patient 
Table 1: Demographic data, symptom ratings and medication.

\begin{tabular}{|c|c|c|}
\hline & Schizophrenia Group & Control Group \\
\hline $\mathrm{N}$ & 12 (8 male) & 12 (8 male) \\
\hline N (ERP component) & 12 (8 male) & 12 (8 male) \\
\hline N (fMRI component) & 11 (8 male) & 11 (8 male) \\
\hline Age & $36.75(8.41)$ & $37.42(8.17)$ \\
\hline Years of Education $^{1}$ & $3.67(1.31)$ & $4.57(0.94)$ \\
\hline $\begin{array}{l}\text { Global Assessment of } \\
\text { Functioning }\end{array}$ & $39.60(14.69)^{* *}$ & $68.67(13.10)$ \\
\hline \multicolumn{3}{|l|}{ SAPS } \\
\hline Hallucinations & $4.82(4.96)^{* *}$ & - \\
\hline Delusions & $7.00(5.81)^{* *}$ & - \\
\hline Bizarre Behaviour & $1.91(2.73)^{*}$ & $0.08(0.29)$ \\
\hline Thought Disorder & $5.27(7.43) *$ & - \\
\hline \multicolumn{3}{|l|}{ SANS } \\
\hline Affect & $7.27(8.68)^{* *}$ & $1.67(0.58)$ \\
\hline Alogia & $2.18(2.82)^{* *}$ & - \\
\hline Avolition & $7.09(4.93)^{* *}$ & $0.42(1.44)$ \\
\hline Anhedonia & $7.45(4.25)^{* *}$ & $0.67(2.31)$ \\
\hline Attention & $3.00(3.16)^{* *}$ & $0.33(1.15)$ \\
\hline \multicolumn{3}{|l|}{ Medication $^{2}$} \\
\hline Atypical antipsychotics & 11 & - \\
\hline Typical antipsychotics & 1 & - \\
\hline Mood Stabilisers & 1 & - \\
\hline Sedatives & 1 & - \\
\hline \multicolumn{3}{|c|}{$\begin{array}{l}\text { Standard deviation is shown in parentheses. }{ }^{1} \text { Based on a } 5 \text {-pont scale where } 1=\text { some primary, } 2=\text { some } \\
\text { secondary, } 3=\text { some secondary plus trade } 4=\text { completed secondary, } 5=\text { begun tertiary. }{ }^{2} \text { Note that some } \\
\text { patients were on more than one type of medication. Medication information was not available for two } \\
\text { patients, and two were currently off medication. Asterisks indicate significant differences from } \\
\text { control } *: p<.05 * *: p<.01\end{array}$} \\
\hline
\end{tabular}


Table 2: Switching with anticipatory preparation: Informatively cued switch $>$ repeat. Contrasts were thresholded at $\mathrm{p}<.005$ (uncorrected), followed by a cluster-wise threshold of $\mathrm{p}<.05$ (corrected for multiple comparisons, $\mathrm{K}=11$ contiguous voxels). Coordinates are in Talairach space.

\begin{tabular}{|c|c|c|c|c|}
\hline \multirow[b]{2}{*}{ Region (BA) } & \multicolumn{2}{|c|}{ Left Hemisphere } & \multicolumn{2}{|c|}{ Right Hemisphere } \\
\hline & Tal & $\mathrm{T}$ & Tal & $\mathrm{T}$ \\
\hline \multicolumn{5}{|l|}{ Switch > Repeat } \\
\hline \multicolumn{5}{|l|}{ Control } \\
\hline \multicolumn{5}{|l|}{ Frontal } \\
\hline Superior/Medial Frontal Gyrus (6) & $-8,-16,71$ & 4.72 & - & - \\
\hline Middle Frontal Gyrus (9) & $-32,40,32$ & 5.87 & - & - \\
\hline \multicolumn{5}{|l|}{ Parietal } \\
\hline Precuneus (7) & $-8,-64,44$ & 9.02 & $12,-80,45$ & 7.01 \\
\hline \multicolumn{5}{|l|}{ Temporal/Cerebellar } \\
\hline Lingual Gyrus (18) & $-12,-74,-3$ & 5.82 & $16,-88,-4$ & 4.89 \\
\hline Declive & $-40,-63,-20$ & 3.51 & $4,-67,-20$ & 6.87 \\
\hline Culmen & $-28,-59,-24$ & 4.57 & $40,-56,-24$ & 5.11 \\
\hline \multicolumn{5}{|l|}{ Schizophrenia } \\
\hline \multicolumn{5}{|l|}{ Frontal/Parietal } \\
\hline Inferior Frontal Gyrus (9) & $-48,6,33$ & 4.49 & - & - \\
\hline Precuneus (7) & $0,-67,55$ & 4.63 & - & - \\
\hline \multicolumn{5}{|l|}{ Cerebellar } \\
\hline Declive & $-4,-71,-20$ & 4.21 & - & - \\
\hline $\begin{array}{l}\text { Schizophrenia vs. Control } \\
\text { No suprathreshold voxels }\end{array}$ & & & & \\
\hline
\end{tabular}


Table 3: Repeating with anticipatory preparation: Repeat $>$ Switch. Contrasts were thresholded at $\mathrm{p}<.005$ (uncorrected), followed by a cluster-wise threshold of $\mathrm{p}<.05$ (corrected for multiple comparisons, $\mathrm{K}=11$ contiguous voxels). Coordinates are in Talairach space.

\begin{tabular}{|c|c|c|c|c|}
\hline \multirow[b]{2}{*}{ Region (BA) } & \multicolumn{2}{|c|}{ Left Hemisphere } & \multicolumn{2}{|c|}{ Right Hemisphere } \\
\hline & Tal & $\mathrm{T}$ & Tal & $\mathrm{T}$ \\
\hline \multicolumn{5}{|l|}{ Repeat $>$ Switch } \\
\hline \multicolumn{5}{|l|}{ Control } \\
\hline Middle Temporal Gyrus (19) & - & - & $48,-61,18$ & 4.47 \\
\hline \multicolumn{5}{|l|}{ Schizophrenia } \\
\hline \multicolumn{5}{|l|}{ Frontal } \\
\hline Superior Frontal Gyrus (8/9/10) & $-16,48,31$ & 6.17 & 16, 49, 38 & 5.71 \\
\hline Middle Frontal Gyrus (8) & $-28,18,40$ & 6.17 & - & - \\
\hline Medial Frontal Gyrus (8) & $-16,32,44$ & 5.31 & 4, 52, 28 & 4.38 \\
\hline Cingulate (24) & $-16,-17,41$ & 4.83 & - & - \\
\hline Insula & - & - & $36,-15,12$ & 5.37 \\
\hline Precentral Gyrus (6) & - & - & $48,-18,23$ & 4.37 \\
\hline \multicolumn{5}{|l|}{ Parietal/Temporal/Occipital } \\
\hline Precuneus (7) & $-16,-45,32$ & 4.73 & - & - \\
\hline Posterior Cingulate (29) & $-12,-49,21$ & 4.55 & - & - \\
\hline Superior Temporal Gyrus (38) & - & - & $40,-1,-17$ & 4.05 \\
\hline Middle Temporal Gyrus (21) & $-60,-12,-9$ & 5.10 & - & - \\
\hline Middle Occipital Gyrus (37) & - & - & $44,-70,7$ & 5.03 \\
\hline \multicolumn{5}{|l|}{ Subcortical } \\
\hline Thalamus & & & $24,-24,5$ & 4.75 \\
\hline \multicolumn{5}{|l|}{ Schizophrenia vs. Control } \\
\hline \multicolumn{5}{|l|}{ Frontal } \\
\hline Superior Frontal Gyrus (9) & $-16,52,31$ & 5.16 & - & - \\
\hline Middle Frontal Gyrus (9) & $-28,21,32$ & 3.70 & - & - \\
\hline Medial Frontal Gyrus (8) & $-16,33,39$ & 4.75 & 12, 33, 35 & 5.65 \\
\hline Cingulate (24/32) & $-4,29,28$ & 3.54 & $4,17,29$ & 4.69 \\
\hline \multicolumn{5}{|l|}{ Temporal } \\
\hline Parahippocampal Gyrus (19) & $-24,-46,-4$ & 7.31 & - & - \\
\hline Lingual Gyrus (18) & $-32,-58,-4$ & 4.03 & - & - \\
\hline \multicolumn{5}{|l|}{ Subcortical } \\
\hline Red Nucleus & $-4,-24,-6$ & 7.14 & $4,-20,-2$ & 7.52 \\
\hline
\end{tabular}


Table 4: Correlations between behavioural, ERP and fMRI measures for the switch $>$ repeat contrast. Contrasts were thresholded at $\mathrm{p}<.005$ (uncorrected), followed by a cluster-wise threshold of $\mathrm{p}<.05$ (corrected for multiple comparisons, $\mathrm{K}=11$ contiguous voxels). Coordinates are in Talairach space.

\begin{tabular}{|c|c|c|c|c|c|c|}
\hline \multirow[b]{2}{*}{ Region (BA) } & \multicolumn{3}{|c|}{ Left Hemisphere } & \multicolumn{3}{|c|}{ Right Hemisphere } \\
\hline & Tal & $\mathrm{T}$ & $\mathrm{R}$ & Tal & $\mathrm{T}$ & $\mathrm{R}$ \\
\hline \multicolumn{7}{|l|}{ Switch $>$ Repeat \& switch cost } \\
\hline \multicolumn{7}{|l|}{ Control } \\
\hline \multicolumn{7}{|l|}{ Frontal } \\
\hline Middle Frontal Gyrus (10) & $-36,40,20$ & 5.06 & .57 & $36,48,20$ & 6.20 & .91 \\
\hline Inferior Frontal Gyrus (45) & $-40,-20,12$ & 4.53 & .85 & - & - & - \\
\hline Precentral Gyrus (6) & $-48,-2,37$ & 5.46 & .76 & - & - & - \\
\hline Cingulate (32) & - & - & - & $0,17,29$ & 8.03 & .94 \\
\hline \multicolumn{7}{|l|}{ Parietal } \\
\hline Precuneus (7) & $-24,-71,48$ & 10.87 & .97 & $12,-64,44$ & 4.08 & .82 \\
\hline Posterior Cingulate (30) & - & - & - & $4,-38,20$ & 6.65 & .92 \\
\hline \multicolumn{7}{|l|}{ Cerebellar } \\
\hline Declive & - & - & - & $28,-64,-20$ & 12.96 & .98 \\
\hline Dentate & - & - & - & $20,-59,-24$ & 8.58 & .95 \\
\hline Culmen & - & - & - & $36,-56,-24$ & 7.50 & .94 \\
\hline Tonsil & $-24,-60,-31$ & 5.72 & .90 & - & - & - \\
\hline \multicolumn{7}{|l|}{ Schizophrenia } \\
\hline \multicolumn{7}{|l|}{ Frontal/Parietal } \\
\hline Precentral Gyrus (6) & - & - & - & $28,-16,67$ & 5.89 & .90 \\
\hline Precuneus (7) & $-20,-76,37$ & 7.12 & .93 & $8,-71,48$ & 5.01 & .87 \\
\hline \multicolumn{7}{|l|}{ Occipital/Cerebellar } \\
\hline Inferior Occipital Gyrus (18) & - & - & - & $28,-90,-6$ & 5.66 & .89 \\
\hline Cuneus (19) & - & - & - & $0,-76,33$ & 4.55 & .85 \\
\hline Declive & - & - & - & $4,-71,-13$ & 4.89 & .87 \\
\hline \multicolumn{7}{|l|}{ Switch > Repeat \& switch-positivity } \\
\hline \multicolumn{7}{|l|}{ Control } \\
\hline \multicolumn{7}{|l|}{ Frontal/Parietal } \\
\hline Middle Frontal Gyrus (6) & - & - & - & $32,-5,56$ & 5.39 & .89 \\
\hline Inferior Frontal Gyrus (47) & - & - & - & $48,19,-1$ & 6.75 & .92 \\
\hline Cingulate (24) & - & - & - & $0,17,25$ & 8.78 & .95 \\
\hline Inferior Parietal Lobule (40) & $-51,-34,27$ & 8.09 & .94 & - & - & - \\
\hline \multicolumn{7}{|l|}{ Temporal/Occipital } \\
\hline Superior Temporal Gyrus (22) & $-59,-42,21$ & 11.72 & .97 & $51,7,-7$ & 4.65 & .85 \\
\hline Fusiform (19) & - & - & - & $28,-63,-7$ & 10.36 & .96 \\
\hline \multicolumn{7}{|l|}{ Schizophrenia } \\
\hline \multicolumn{7}{|l|}{ Frontal/Parietal } \\
\hline Middle Frontal Gyrus (6) & $-20,3,62$ & 7.63 & .94 & - & - & - \\
\hline Precuneus (7) & $-8,-67,51$ & 7.36 & .93 & $8,71,48$ & 7.36 & .93 \\
\hline
\end{tabular}


Table 5: Correlations between switch > repeat contrast and amplitude of the switch-negativity over $300-400 \mathrm{~ms}$ and $500-600 \mathrm{~ms}$. Contrasts were thresholded at $\mathrm{p}<.005$ (uncorrected), followed by a cluster-wise threshold of $\mathrm{p}<.05$ (corrected for multiple comparisons, $\mathrm{K}=11$ contiguous voxels).

Coordinates are in Talairach space.

\begin{tabular}{lcccccc} 
& \multicolumn{3}{c}{ Left Hemisphere } & \multicolumn{3}{c}{ Right Hemisphere } \\
\cline { 2 - 6 } Region (BA) & Tal & T & R & Tal & T & R
\end{tabular}

Switch > Repeat \& switch-negativity 300-400ms

\section{Control}

$\begin{array}{lllllll}\text { Medial Frontal Gyrus (10) } & -4,61,1 & 4.27 & .95 & 8,58,-13 & 4.26 & .83\end{array}$

\section{Schizophrenia}

Cingulate Cortex (24)

Precentral Gyrus (6)

Globus Pallidus

$\begin{array}{ccc}-8,5,22 & 5.39 & .89 \\ -44,-14,30 & 5.16 & .88\end{array}$

Cuneus (23)

$-24,-12,0$

4.99

.87

$-$

$-$

\begin{tabular}{cccc}
89 & $8,5,22$ & 7.57 & .94 \\
.88 & - & - & - \\
87 & - & - & - \\
- & $8,-76,8$ & 5.92 & .90 \\
\hline
\end{tabular}

Switch > Repeat \& switch-negativity 500-600ms

\section{Control}

Middle Frontal Gyrus (10)

Cingulate Cortex (24)

Precentral Gyrus (4/6)

Inferior Parietal Lobule (40)

Superior Temporal Gyrus

Fusiform Gyrus

\section{Schizophrenia}

Medial Frontal Gyrus (10)

Inferior Parietal Lobule (40)

Middle Temporal Gyrus (39)

$\begin{array}{cccccc}-32,43,13 & 9.07 & .95 & - & - & - \\ -12,-6,33 & 3.57 & .78 & 4,-14,34 & 5.82 & .90 \\ - & - & - & 36,-18,34 & 5.24 & .88 \\ - & - & - & 55,-46,21 & 5.13 & .87 \\ - & - & - & 51,-46,13 & 5.03 & .87 \\ - & - & - & 36,-55,-7 & 6.95 & .93 \\ - & - & & & & \\ - & - & - & 8,55,19 & 5.36 & .88 \\ - & - & - & 60,-53,25 & 7.62 & .94 \\ - & - & - & 56,-68,24 & 4.10 & .82\end{array}$

